\title{
Security durability assessment through Fuzzy Analytic Hierarchy process
}

\author{
Alka Agrawal ${ }^{1}$, Mohammad Zarour $^{2}$, Mamdouh Alenezi $^{2}$, Rajeev Kumar ${ }^{1}$, Raees Ahmad Khan ${ }^{\text {Corresp. } 1}$ \\ 1 Information Technology, Babasaheb Bhimrao Ambedkar University, Lucknow, UP, India \\ 2 College of Computer \& Information Sciences, Prince Sultan University, Riyadh, Saudi Arabia \\ Corresponding Author: Raees Ahmad Khan \\ Email address: khanraees@yahoo.com
}

Background: Security is an integral aspect of the development of quality software. Furthermore, security durability is even more imperative and in persistent demand due to high investment in recent years. To achieve the desired target of efficacious and viable durability of security services, there needs to be nodal focus on durability along with security. Unfortunately, the highly secure design of software becomes worthless because the durability of security services is not as it should be. Methods: Security durability attributes have their own impact while integrating security with durability and assessment of security durability plays a crucial role during software development. Within this context, this paper estimates the security durability of the two alternatives versions of a locally developed software called version 1 and version 2 . To assess the security durability, authors are using the hybrid fuzzy analytic hierarchy process decision analysis approach. Results: The impact of the security durability on other attributes has been evaluated quantitatively. The result obtained contains the assessment of security durability. The study posits conclusions which are based on this result and are useful for practitioners to assess and improve the security life span of software services. 


\title{
1 Security Durability Assessment through Fuzzy 2 Analytic Hierarchy Process
}

3

\author{
Alka Agrawal ${ }^{1}$, Mohammad Zarour ${ }^{2}$, Mamdouh Alenezi ${ }^{2}$, Rajeev Kumar ${ }^{1}$, Raees Ahmad Khan ${ }^{1}$ \\ ${ }^{1}$ Information Technology, Babasaheb Bhimrao Ambedkar University, Lucknow, UP, India \\ ${ }^{2}$ College of Computer \& Information Sciences, Prince Sultan University, Riyadh, Saudi Arabia \\ Corresponding Author: Raees Ahmad Khan \\ Email address: khanraees@yahoo.com
}

\section{Abstract}

Background: Security is an integral aspect of the development of quality software. Furthermore, security durability is even more imperative and in persistent demand due to high investment in recent years. To achieve the desired target of efficacious and viable durability of security services, there needs to be nodal focus on durability along with security. Unfortunately, the highly secure design of software becomes worthless because the durability of security services is not as it should be.

Methods: Security durability attributes have their own impact while integrating security with durability and assessment of security durability plays a crucial role during software development. Within this context, this paper estimates the security durability of the two alternatives versions of a locally developed software called version 1 and version 2 . To assess the security durability, authors are using the hybrid fuzzy analytic hierarchy process decision analysis approach.

Results: The impact of the security durability on other attributes has been evaluated quantitatively. The result obtained contains the assessment of security durability. The study posits conclusions which are based on this result and are useful for practitioners to assess and improve the security life span of software services.

\section{Introduction}

Security specialists are confronting with various issues to comprehend the new security challenges at the initial phases of software development. There is a ceaseless burden on the developers to maximize the development and at the same time lessen the expense and time invested in security to optimise the financial dividends of the organization. The nature of software development is becoming even more perplexing at each step with the requirement for security expanding in each field. Evaluating and looking after Confidentiality, Integrity, and Availability (CIA) amid phases of programming advancement has ended up being an 
extraordinary task as compared to other approaches to get more secure software [1-2]. Security in the product must be consolidated in software development advancement from the earliest starting point and it ought to proceed till the software is being used [3]. Consolidating security amid security improvement prompts reduction of development budget and effort. It must not be forgotten by security specialists when the advancement of software security development is finished or it ought not to be dealt with at the late stage of software development.

As per the predictions done by 31 experts of software security of PhoenixNAP IT services at the end of year 2018, machine learning technologies with smartphones are going to be new challenges to conquer by security practitioners [4]. These predictions produced major contribution in the area of life span of security of software including many macro levels direct or indirect findings. The estimation practice at early stage is beneficial for secure and durable software development. Also According to a technical report, Software-as-a-Service (SaaS) operations and Management Company, about 73 percent of the organizations expect to shift nearly all of their applications to Software as a Service by 2020 and want to improve the lifespan of services [5]. Organization of CA Veracode tested a scan of 400,000 numbers on their clients' software in a one-year period which started in April 2016 [7]. In these scans, they found 12.8 million flaws. According to the report, it was found that stakeholders who use antivirus software to scan the improvements of security were able to detect at least one vulnerability during the initial scan. About one in eight were found to be of high or very high severity vulnerability related to life span of security services.

In 2016, companies closed only $58 \%$ of vulnerabilities in the same calendar year in which they were found. And the percentage of companies that successfully passed checks for weaknesses on the OWASP Top 10 list declined to $35 \%$ for internally developed software, down from $39 \%$ in the last year's report. Third-party code, which typically has more vulnerabilities, also performed worse year after year as only $23 \%$ passed the OWASP Top 10 check. This was down from $25 \%$ in the previous year. Globally, the data shows that organizations are trying hard to stay away from vulnerabilities and doing the security checks on a regular basis. Yet there is something missing, and secure software for a long time seems to be a mirage. Therefore, developers need to understand how to relate security attributes with those of durability and measure the impact of these attributes for enhancing secure life span of software. Assessment of security durability attributes is necessary to ensure long term security [5]. Outcomes of evaluation process may allow decision makers to make appropriate decision as well as propel action [6-7]. However, to be able to take appropriate action, decision makers are not only need to know about security and durability attributes but their mapping also.

Multi-Criteria Decision Analysis (MCDA) approach is a discipline which aims to support experts when they are faced with various conflicting items for evaluation [9]. The MCDA approach is very suitable to take two or more conflicting problems side by side. Various MCDA methods are available including Analytic Hierarchy Process (AHP), Fuzzy Analytic Hierarchy Process (fuzzy AHP), and Multi-Attribute Utility Theory (MAUT) [8-9]. All these approaches are differentiated by the way the objectives and alternative weights that are determined through it. Although AHP is 
82 considered good while analyzing a decision in a group, various researchers have found that

83

84

85

86

87

88

89

90

91

92

93

94

95

96

97

98

99

100

101

102

103

104

105

106

107

108

109

110

111

112

113

114

115

116

117

118

119

120

121

122

123

124

125

hybrid AHP is better in providing crisp decisions with their weights too [10].

Hence in order to deal with the uncertainty and ambiguity of human judgment, the authors have used a hybrid version of AHP (also known as fuzzy AHP) which incorporates fuzzy set theory with AHP methodology [10-11] to evaluate security durability of software services. This paper presents an approach for evaluating life span of security services.

The results help to formulate development strategies to achieve the desired security durability. This may help software developers to come up with durable as well as secure software. According to the structure of the paper, firstly, authors reviewed the literature available on the signified area. In the section of materials and methods, the authors have introduced security durability and are using one of the most famous MCDA techniques which is called the fuzzy analytic hierarchy process to evaluate weights of the security durability attributes. In the next section of paper with the help of these weights, the authors have categorized the most important attributes at each level and proposed some suggestions to improve the life span of security of software. To evaluate the ratings of the attributes of security durability, two successive versions of a case study have been taken, i.e., entrance examination software for Babasaheb Bhimrao Ambedkar University, Lucknow, India (BBAU Software). Thereafter, in the next sections, the authors have assessed security durability and given suggestions for practitioners based on it. In the last section, the results, discussion and conclusion have been profiled.

\section{Literature Review}

The digital age has made software an elemental aspect of everyone's life in various forms such as to share data, to communicate, to maintain databases, etc. Almost every facet of life today is connected with some kind of software be it through banking, health, education, engineering, social realms or others. Hence, all information related to software must be secure and the demand for secure software has increased today. Software security can be termed as the idea to secure software from malicious attacks and fraudulent persons or hackers [12-13]. Many experts have discussed many areas of security including security attributes, security management, security maintenance, etc., but still, there is something missing. Organizations are investing both money and resources to optimize the maintenance of security for improving the life span of the software [13]. Yet, they have not been successful. Some of the pertinent efforts of the practitioners to assess and improve the security of software are discussed below:

In 2019, Charles Weir et al. proposed a common framework of security assurance for developers [14]. The framework defined the problem in security awareness and organized a three month light weighted security assurance workshop. The workshop focused on security assurance. Based on the report, the authors have given a common guideline for developers to improve the skills to increase the security services while the software is in use. The adoption of this process plays a key role in improving software security for the end users. In 2018, Dayanandan U. et al. evaluated the quality for security analysis [15]. Authors of the paper proposed a framework for quality assessment at software architecture level. The assessment focused on security because it is the

Peer) Comput. Sci. reviewing PDF | (CS-2019:03:35600:1:2:NEW 14 Jun 2019) 
126 key attribute of quality. The relationship between quality and object oriented design properties has

127 been well established. And fuzzy AHP method has been used to evaluate the results. For the validation of the framework, authors have used four versions of apache Tomcat series.

129

130

131

132

133

134

135

136

137

138

139

140

141

142

143

144

145

146

147

148

149

150

151

152

153

154

155

156

157

158

159

160

161

162

163

164

165

166

167

168

169

In 2017, Davoud Mougouei defined the modeling process through quantitative assessment [13]. The author defined the problem in existing prioritization techniques for security attributes and the needs of prioritization of attributes. These are usually ignored and thus give birth to new but insecure software. To address it, the author proposed to consider the partial satisfaction of security needs when tolerated rather than ignoring those security needs for the future. As a result, this research has contributed a framework that prioritizes and selects security requirements. In 2016, Friedrich Praus et al. examined the security and software architecture through a critical survey [16]. The authors presented a research on software security requirements in building automation. Their paper provided an extensive survey of the security requirements for distributed control applications and analyzed software protection methods. Architecture on the same problem has been defined that works to secure software that runs on different devices or classes. This architecture also prevents attacks on smart homes and buildings.

Along with fixing security issues, the design of security should also be strong. Hence to improve the security, designing is the main point during secure software development. With the emergence of new threats, new security issues are being generated day by day. Fixing these latest security issues requires more investment in maintenance cost. Time incorporated in security development also increases. However, there is persistent pressure from the users' end to minimize on both the time and cost. Many practitioners are trying to fill the hole of security design so that new threats are removed and security services are enhanced with it. To improve the software's service life, security life span should be improved.

The following literature review underlines the security durability of software services:

In 2017, Celia Chen defined the maintainability as a big concern for non-durable software [17]. The author described: "Why Is It Important to Measure Maintainability and What Are the Best Ways to Do It?". Her study discussed that the durability of software is improved by reducing the cost and time involved in maintenance. The author discussed that there are metrics that can help software developers to measure and analyze the maintainability of a project objectively. This research paper addressed the importance of understanding software maintainability, gave a framework and some of the best ways to measure maintainability. In the same year, Alarifi A. et al. proposed a structured inspection model for thoroughly evaluating the usability and security of internal and external e-banking assets [18]. The authors have also demonstrated the insufficiency of existing security- usability models and have also applied their proposed framework to evaluate five major banks. The results clearly reflect several shortcomings regarding the security and privacy features in banks.

In 2015, Kelty C. and Erickson S. addressed maintainability issues [19]. The authors stated that the design is responsible for less durable software. The authors discussed about achieving durable software with optimal maintenance. According to the authors, the durability of software depends on its different applications such as a social, economic and cultural field. Durability is a

Peer] Comput. Sci. reviewing PDF | (CS-2019:03:35600:1:2:NEW 14 Jun 2019) 
170

171

172

173

174

175

176

177

178

179

180

181

182

183

184

185

186

187

188

189

190

191

192

193

194

195

196

197

198

199

200

201

202

203

204

205

206

207

208

209

210

211

212

213

result of robustness and maintainability. The paper explains maintainability as a never-ending process and hence reduces durability. The authors further suggest finding the ways for ensuring the durability of software by design because it still needs to improve for better user experience. In 2014, Security Standards Council addressed the optimal maintenance process of vulnerability for improving security life span [20]. The Council published a special report on the workshop on software measures and metrics to reduce security vulnerabilities. The goal of the report was to gather ideas on how the federal government can identify, improve, package, deliver, or boost the use of software measures, metrics to significantly reduce vulnerabilities and enhance the working life of software with optimal maintainability. The report contains observations and recommendations from the workshop's participants. The report includes position statements submitted to the workshop, presentations at the workshop and related material.

In 2014, Nathan Ensmenger defined that maintainability plays a key role in decreasing the durability of software but the solution to this problem is not given [21]. The author says that software durability and software serviceability are two faces of the same coin. There is a significant issue of long-time services and increased cost spent on the maintenance of software. Further, the author discusses working life of durability which decreases as the time passes. Hence, for long-term software, durability does play a key role. The study also related durability with maintenance, as time wasted upon the maintenance can be reduced considering the factor of durability in $\mathrm{s} / \mathrm{w}$. In the end, the author concludes that maintenance can be a central issue in the history of software, the history of computing, and the history of technology if it does not deliver durable software. In this context, software developers should focus on security and durability simultaneously during software development to improve the life span of security as well as software. Further, in 1992, Parker D. B. said that long security life span is needed to improve the user's satisfaction related to protecting user's data [22]. He also discussed the challenges of high maintenance of security during the use of software services. Due to the high maintenance cost of security, practitioners are focusing on security design during a specified life span of software.

According to Nathan Ensmenger, in the early 1960s, the development of the IBM OS/360 operating system has taken four years of maintenance time that absorbed more than 5,000 staff years of effort and cost the company more than half-a-billion dollars. This makes it the single biggest expenditure in IBM history [21]. To solve these types of issues, there is a need to address the security durability during software development. Quantitative assessment is one of the most important methods to address, assess and solve any issue. Security design during software development is a very crucial task. There are so many factors that affect the security and durability simultaneously including CIA. Every organization has its own methods and logic to develop the security as well as software design. All in all, this is a multiple decision analysis problem in perspective of the durability of security, that's why researchers have taken an MCDA technique to assess the security durability.

\section{Security Durability of Software}

The importance of software in our lives is growing daily. People's personal and professional lives can greatly be enhanced by the presence of highly secure and durable software and can greatly

Peer) Comput. Sci. reviewing PDF | (CS-2019:03:35600:1:2:NEW 14 Jun 2019) 
214 be imposed upon by the presence of poor quality software. Most complex software systems, such 215 as airplane flight control or nuclear power plants, depend critically upon the durability of their 216 secure software. In today's world, organizations are busy in understanding and mitigating security 217 challenges during the software development life cycle. There are some key characteristics of the 218 security and focusing on those may help to address these challenges directly or indirectly. One of 219 these characteristics is durability. It may also be called as working life or longevity of security [21].

220

221

222

223

224

225

226

227

228

229

230

231

232

233

234

235

236

237

238

239

240

241

242

243

244

245

246

247

248

249

250

251

252

253

254

255

256

257

258
The ability of software to secure itself for the expected life-span

or

The ability of software to withstand attacks for the expected life-span

Durability means how long a software security solution will function effectively and meet the security requirements. There are several reasons for organizations to integrate durable security during software development as:

- To provide longer security in the given service environment, thereby mitigating security challenges [3].

- To reduce maintenance time by reducing the effort needed to fix bugs by delivering durable and secure software [6].

These are two main reasons to examine the security and durability simultaneously for addressing, assessing and improving the security durability. There are so many attributes of security and durability which are related to each other. These attributes are useful in assessing security durability. Further, the authors' previous works are identified and classify the security durability attributes [24] which are discussed in next sections.

\section{Materials \& Methods}

\section{Methodology of Assessment}

Security is one of the most important quality properties of software which is concerned with both end users and developers [5]. Security estimation plays a key role in improving the quality of software. Durability plays a key role in enhancing the security life span [18]. To improve the security life span of software, security durability assessment is essential which may be helpful for security policy, goals, etc., and user's satisfaction. Security cannot be durable until security durability is not measured. To assess security durability, multiple criteria decision analysis method is well suited because of the advantage of assessing any attribute with multiple sub properties by this method. Analytic Hierarchy Process (AHP) is very popular in troubleshooting such problems.

Major benefit of AHP is its relative simplicity with which it handles multiple criteria. AHP allows decision makers to mould a complex problem in a hierarchical structure that consists of the goal, aims, sub-objectives, and alternatives. Traditional methods of AHP cannot be used when there is

Peer] Comput. Sci. reviewing PDF | (CS-2019:03:35600:1:2:NEW 14 Jun 2019) 
259

260

261

262

263

264

265

266

267

268

269

270

271

272

273

274

275

276

277

278

279

280

281

282

283

284

285

286

287

288

289

290

291

292

293

294

295

296

297

298

299

300

301

302

303

304

uncertainty in data [20]. To address such uncertainties, fuzzy set theory was first introduced. Many times, priority assessment of different attributes usually fails because of the connection of multiple qualitative criteria. Fuzzy AHP is a suitable evaluation technique capable of handling this kind of problem with uncertain inputs

\section{Implementation}

In order to address the fundamental difficulty of security durability assessment, researchers have taken a hybrid method, i.e., Fuzzy AHP methodology. Although, AHP is considered good while analyzing a decision in a group, various researchers have found that hybrid AHP is better for providing crisp decisions with their weights too [25]. Hence, in order to deal with the uncertainty and ambiguity of researchers and academicians, the authors have used a hybrid version of AHP (also known as fuzzy AHP) which incorporates fuzzy set theory with AHP methodology [26], to evaluate security durability of software. The adopted methodology is given in figure 1 that is in the form of a flow chart. The flow chart describes the process of security durability assessment. It has been divided into five phases/steps including planning; fuzzification; fuzzy operations; defuzzification; and analysis, confirmation \& estimation. Planning phase deals with problem recognition, selecting the alternatives for the problem and defines the scope\& boundaries of the analytic hierarchy process. Fuzzification phase deals with the preliminary process of methodology including defining the membership function with a scale. Fuzzy operations phase deals with the performance of pair-wise comparison matrixes through triangular fuzzy numbers with the help of the expert's opinions. Defuzzification phase deals with the transformation of fuzzified weights into defuzzified linguistic values while the last phase deals with weights, ratings, and assessment. Further, the last phase also deals with improvement (performance), sensitivity analysis and validation of the results through statistical analysis. The phase-wise description of the methodology is given in subsections as:

\section{Figure 1: Flow Chart of the Implementation through Fuzzy AHP Method}

\section{a) Planning Phase}

The problem of security durability is recognized, addressed in previous sections and related attributes of security durability are identified, categorized in previous work of the authors [25]. $\mathrm{AHP}$ is used as a decision-making tool for estimating the priority numbers for different alternatives with a hierarchical structure of multiple criteria [24]. According to this research, AHP is best suited for choosing the apt alternatives among the number of options while fuzzy is best in dealing with linguistic variables. That's why Fuzzy AHP has been used in this work for better results.

\section{b) Fuzzification Phase}

To understand the Fuzzy Analytical Hierarchy Process (Fuzzy AHP) methodology, researchers have included a short introduction of both methods and hybridization of them. Saaty defines the Analytic Hierarchy Process (AHP) as a decision method which decomposes a complex multicriteria decision problem into a hierarchy [27]. The major benefit of AHP is its relative simplicity with which it handles multiple criteria. AHP allows decision makers to mould a complex problem in a hierarchical structure that consists of the goal, aims, sub-objectives, and alternatives. Traditional methods of AHP cannot be used when there is uncertainty in data. To address such uncertainties, the fuzzy set theory was merged into the AHP. In 1965, Zadeh introduced the fuzzy set theory to

Peer] Comput. Sci. reviewing PDF | (CS-2019:03:35600:1:2:NEW 14 Jun 2019) 
305

306

307

308

309

310

311

312

313

314

315

316

317

318

319

320

321

322

323

324

325

326

327

328

329

330

331

332

333

334

335 deal with the uncertainty due to imprecision and vagueness [28]. A fuzzy set is a class of objects with a graded continuum of membership. Such a set is characterized by a membership function which assigns to each object a membership grade between zero and one. In order to simplify the fuzzy AHP method for this research from the feasible viewpoints, the Fuzzy AHP based on the fuzzy interval arithmetic with triangular fuzzy numbers has been proposed.

In the context of the problem addressed in the present work, Fuzzy AHP has been used for prioritizing security durability attributes. Triangular fuzzy number helps the decision maker to make easier decisions [26]. Hence in this paper triangular fuzzy numbers are used as a membership function. Figure 2 depicts a triangular fuzzy number.

\section{Figure 2: Triangular Fuzzy Number}

In this figure $2, \mu_{x}$ is denoted as a membership function where $\mu$ denotes membership value of corresponding $\mathrm{x}$. The parameters, $l, m$ and $h$ denote the smallest possible value, the most promising value, and the largest possible value, respectively, that describes a fuzzy event. Further, a Triangular Fuzzy Number (TFN) $\left(\mu_{i j}\right)$ is simply denoted as $(I, m, h)$. The triangular fuzzy number $\mu_{\mathrm{ij}}$ is represented in equation (1):

$$
\begin{gathered}
\mu_{i j}=\left(l_{i j}, m_{i j}, h_{i j}\right) \ldots \ldots \ldots \ldots \ldots(1) \\
\text { where } l_{i j} \leq m_{i j} \leq h_{i j} \operatorname{andl}_{\mathrm{ij}}, \mathrm{m}_{\mathrm{ij}}, \mathrm{h}_{\mathrm{ij}} \in[1 / 9,9] \\
l_{i j}=\min \left(B_{i j k}\right), \\
m_{i j}=\left(B_{i j 1} \cdot B_{i j 2} \ldots \ldots \ldots \ldots B_{i j k}\right) 1 / k \\
\text { and } h_{i j}=\max \left(B_{i j k}\right)
\end{gathered}
$$

Where $B_{i j k}$ represents the judgment of experts, $\mathrm{k}$ for the importance of two criteria i.e. $C_{i}$ and $C_{j}$ Since each number in the pair-wise comparison matrix represents the subjective opinion of decision makers and is an ambiguous concept, fuzzy numbers work best to consolidate fragmented expert opinions [25-26]. Saaty proposed pair-wise comparisons to create the fuzzy judgment matrix that is used in the AHP technique [27] and is shown in equation 2.

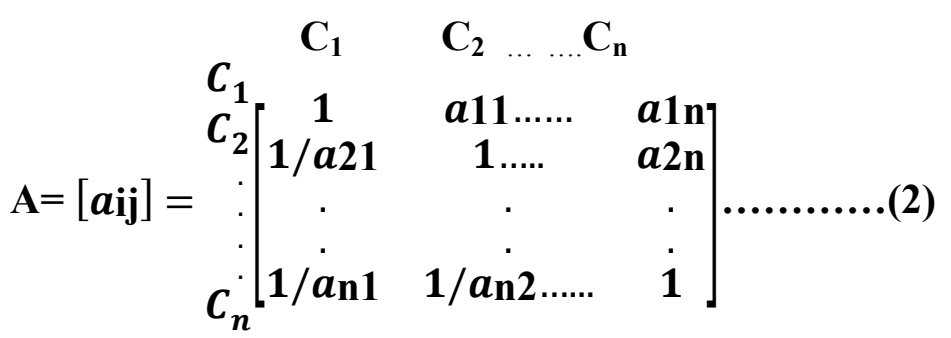

Where $i=1,2,3 \ldots \ldots \ldots n$ and $j=1,2,3 \ldots \ldots \ldots \ldots . n$ and $a_{i j}=1$ : when $i=j$; and $a_{i j}=1 / a_{i j} ;$ when $i \neq j$ where $[\boldsymbol{a} \mathbf{i j}]$ denotes a triangular fuzzy number for the relative importance of two criteria $C_{i}$ and $C_{j}$. Corresponding linguistic scale for membership functions (1 to 9 ) is given in table 1 .

\section{Table 1: Corresponding Linguistic Scale for Membership Functions}

Table 1 shows the linguistic values into numeric values and numeric values into TFN values. TFN values may be used for creating the pair-wise comparison matrix of relative criteria, where $a_{i j}$ denotes the relative importance of criteria $i$ comparison with criteria $j$ in the scale. To determine the weights of each set of attributes, this scale is used in the assessment. Further, the decision made by many experts for security durability is summarized as fuzzy pair-wise 
347

348

349

350

351

352

353

354

355

356

357

358

359

360

361

362

363

364

365

366

367

368

369

370

371

372

373

374

375

376

377

378

379

380

381

382

383

384

385

386

comparison matrixes. It is also used for characterizing the pair-wise fuzzy judgment matrix which is used in AHP technique. For determining the importance of alternatives, linguistic rating scale has been shown in table 2 .

\section{Table 2: Linguistic Rating Scale}

Table 2 shows the rating scale of 0 to 1 in scale as 0.1 describes Very Low (VL), 0.3 describes Low $(\mathrm{L})$ and so on. The associated fuzzy values are assigned to every data got from an expert for a particular alternative. The process of assessment starts with collecting data by the different number of experts. Data can be collected in forms of questionnaires, checklist, etc. The data acquired from the decision makers are compared pair-wise to evaluate the relative importance of each criterion, or the degree of preference of one factor to another with respect to each criterion. However, the perception and judgments of human are represented by linguistic and vague for a complex problem [27].

\section{c) Fuzzy Operations}

After, various linguistic data has been converted into quantitative data into TFN values, to confine the vagueness of the parameters which are related, alternatives such as triangular fuzzy numbers are used [46]. To aggregate all data into a single form, fuzzy operations are required. If, two TFNs $\mathbf{M}_{1}=(l 1, m 1, h 1)$ and $\mathbf{M}_{2}=(l 2, m 2, h 2)$ are given. Then, the rules of operations on them are given below in equation 3,4 and 5 .

$(l 1, m 1, h 1)+(l 2, m 2, h 2)=(l 1+l 2, m 1+m 2, h 1+h 2) . .(3)$

$(l 1, m 1, h 1) \times(l 2, m 2, h 2)=(l 1 \times l 2, m 1 \times m 2, h 1 \times h 2) . .(4)$

$\left(l_{1}, m_{1}, h_{1}\right)^{-1}=\left(\frac{1}{h_{1}}, \frac{1}{m_{1}}, \frac{1}{l_{1}}\right)$

These fuzzy operations are used in various research areas for decision making in different fields such as decision making, rating and so on [29]. Further, it is based on the rationality of uncertainty due to imprecision. A major contribution of fuzzy set theory is its capability of dealing with uncertainty.

\section{d) Defuzzification}

After the construction of the comparison matrix, defuzzification is performed to produce a quantifiable value based on the calculated TFN values. The defuzzification method adopted in this work has been derived from [26-28] as formulated in equations (6-9) which are commonly referred to as the alpha cut method.

$$
\begin{array}{llllll}
\mathrm{C}_{1} & \mathrm{C}_{2} & \ldots \ldots & \mathrm{C}_{\mathrm{n}}
\end{array}
$$

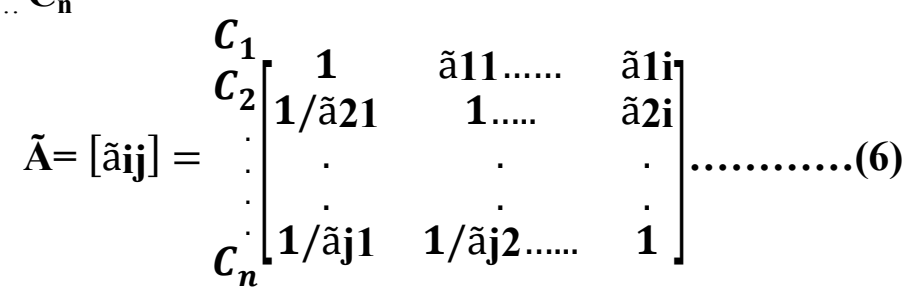

Matrix $\tilde{\mathbf{A}}$ is defined as the defuzzified AHP. Where [ãij]denotes a triangular fuzzy number and shows the relative importance between two criteria $\mathrm{Ci}$ and $\mathrm{Cj}$. There are different defuzzification methods available in the literature such as centroid, the center of sums, alpha 
392

393

394

395

396

397

398

399

400

401

402

403

404

405

406

407

408

409

410

411

412

413

414

415

416

417

418

419

420

421

422

423

cut, etc. [26]. In this work, researchers used the alpha cut method for defuzzification. Alpha cut enables one to describe a fuzzy set as a composition of crisp sets. Crisp sets simply describe whether an element is either a member of the set or not. To defuzzify fuzzy matrix $(\tilde{\mathrm{A}})$ into the crisp matrix $(\rho \boldsymbol{\alpha}, \boldsymbol{\beta})$ is shown in (7-9) (alpha cut method).

$$
\rho \boldsymbol{\alpha}, \boldsymbol{\beta}(\tilde{a} \mathbf{i j})=[\beta . \eta \boldsymbol{\alpha}(\mathrm{lij})+(1-\beta) . \eta \boldsymbol{\alpha}(\mathrm{hij})]
$$

such that,

$$
\text { where } 0 \leq \alpha \leq 1 \text { and } 0 \leq \beta \leq 1
$$

$$
\begin{aligned}
& \eta_{\alpha}\left(l_{\mathbf{i j}}\right)=\left(m_{\mathrm{ij}}-l_{\mathbf{i j}}\right) \cdot \boldsymbol{\alpha}+l_{\mathbf{i j}(8)} \\
& \eta \alpha\left(h_{\mathrm{ij}}\right)=h_{i j}-\left(h_{\mathbf{i j}}-m_{\mathrm{ij}}\right) \cdot \alpha
\end{aligned}
$$

In equations (7-9), na(lij)denotes the left-end boundary value of alpha cut for ãij andna(lij) denotes the right-end boundary value of alpha cut for ãjj.Further, $\alpha$ and $\beta$ carry the meaning of preferences and risk tolerance of participants. Particularly, $\alpha$ and $\beta$ can be stable or in a fluctuating condition. These two values range between 0 and 1 , in such a way that a lesser value indicates greater uncertainty in decision making. Meanwhile, the value of $\alpha$ comes to a stable state when it is increasing particularly. Additionally, $\alpha$ and $\beta$ can be any number between 0 and 1 , and analysis is normally set as the following 10 numbers, $0.1,0.2$, up to 0.9 for uncertainty emulation. Since preferences and risk tolerance are not the focus of this contribution, the value of 0.5 for $\alpha$ and $\beta$ is used to represent a balanced value. This indicates that attributes are neither extremely optimistic nor pessimistic about their comparison. Variation due to the value of $\alpha$ and $\beta$ is discussed in the sensitivity analysis section. The single pair-wise comparison matrix is shown in equation 10.

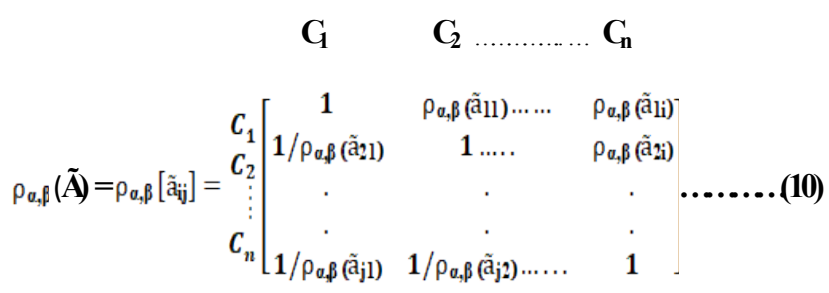

After defuzzification, to validate the consistency of the matrix, next portion of the section has been discussed.

e) Analysis, Confirmation, and Estimation

The next step is to determine the eigenvalue and eigenvector of the fuzzy pair-wise comparison matrix. The purpose of calculating the eigenvector is to determine the aggregated weight of particular criteria. Assume that $W$ denotes the eigenvector, Idenotesunitary matrix while $\lambda$ denotes the eigenvalue of fuzzy pair-wise comparison matrix Ã or[ãij].

$$
\left[\left(\boldsymbol{\rho}_{\boldsymbol{\alpha}, \boldsymbol{\beta}} \times \tilde{\mathrm{A}}\right)-\lambda \times I\right] . W=0
$$

Where $\tilde{A}$ is a fuzzy matrix containing fuzzy numbers of the $\rho_{\alpha, \beta}(\tilde{A})$. Formula (11) is based on the linear transformation of vectors. By applying equations (1-11), the weight of particular criteria with 
424

425

426

427

428

429

430

431

respect to all other possible criteria can be acquired. The eigenvectors of associated attributes of security durability were then calculated using formula (11) as shown in equation 12.

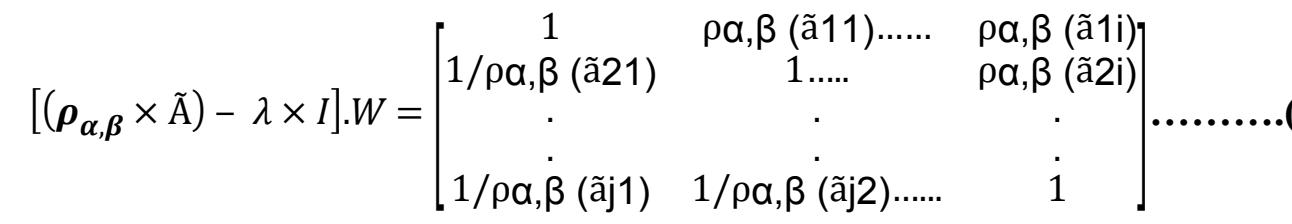

Multiplying eigenvalue $\lambda$ with unitary matrix I produced an identity matrix that cancels out each other. Thus, the notation $\lambda I$ is discarded in this case. Applying formulas (11-12) results are shown in equation 13.

432

433

434

435

436

437

438

439

440

441

442

443

444

445

446

447

448

449

450

451

452

453

454

455

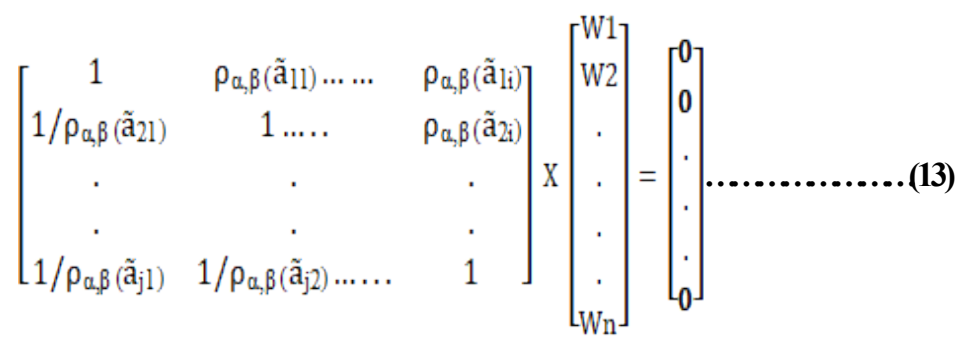

The aggregated results in terms of weights are shown in equation 13.

In order to control the results of the method, the Consistency Ratio (CR) for each of the matrixes for the hierarchal structure is calculated with the help of equation 14.

$$
C R=\frac{C I}{R I} \text {. }
$$

Where Consistency Index denotes as $\mathrm{Cl}$ and Random Index denotes as $\mathrm{RI}$ [27]. Further, $\mathrm{Cl}$ is calculated from equation 15.

$$
C I=\frac{\lambda}{(n-1)}
$$

Where $\mathrm{n}$ denotes the number of total responses and $\mathrm{RI}$ is given by Saaty [27] and given the rank of a matrix as shown in table 3 .

Table 3: Random Index

With the help of equation 14,15 and table $3, C R$ is calculated. If, $C R<0.1$, the approximation is accepted and results are evaluated after this with the help of equation 13; otherwise, a new comparison matrix is solicited.

After calculating the independent weights, this work evaluates the dependent weights and ranks through the hierarchy and results of the obtainable weights gives some suggestion for developers to improve the security durability life span of software services. To assess the effectiveness of results, this work takes two alternatives (version 1 and version 2). Design of version 1 is original from the organization and design of version 2 is changed according to the priorities. Through the hierarchy, authors estimate the independent and dependent ratings of security durability attributes (for version 1 and version 2, respectively) with the help of equations 1, 3, 4, 5 and 7, 8, 9. Then, the authors have assessed the security durability of both alternatives. Overall, the security durability is assessed by equation 16 [30]. 
456

457

458

459

460

461

462

463

464

465

466

467

468

469

470

471

472

473

474

475

476

477

478

479

480

481

482

483

484

485

486

487

488

489

490

491

492

493

494

495

496

497

498

499

500

$$
\text { Security Durability }=R_{1} \times W_{1}+R_{2} \times W_{2}+\ldots \ldots R_{n} \times W_{n}=\Sigma R_{i} \times W_{i} \ldots \ldots
$$

Where $\mathrm{R}$ denotes the rating values, $\mathrm{W}$ denotes the weight of associated attribute and I denotes the number of attributes that affect the security durability. The results clearly underline the impact of the researchers' suggestions and this research work. Further, sensitivity analysis is performed to check the variations on results due to the value of $\alpha$ and $\beta$.

\section{Security Durability Assessment}

A mechanism for security durability assessment has already been discussed in the previous section. According to the mechanism, firstly, researchers will evaluate the local weights of security durability attributes through Fuzzy AHP technique (fuzzy method) and put the local weights in the hierarchy and will find the most important attributes in the form of ranks and their final weights. After this, the authors will give suggestions/guidelines for the developers to improve the security life span of software services. To evaluate the security durability of software and impact of the suggestions, researchers are taking two versions of BBAU software, i.e., version 1 and version 2 where design of version 1 is based on the organizations (called old version) and design of version 2 is modified, according to the given suggestions (called modified version). To assess the best alternative, the ratings of version 1 and version 2 will be evaluated through fuzzy average method [33-34]. With the help of weights (also called subjective weights) and ratings (also called objective weights) of the attributes, overall security durability of version 1 and version 2 will be estimated. The step-by-step process of assessment has been shown in the next portion of the section.

\section{Evaluating the Weights of the Attributes}

Through the previous discussion and literature studies, it is found that integrating durability within design may enhance the potential of CIA [12]. Hence, firstly establishing a relation between durability and security is important. Security of a software product is durable if it works efficiently for user's satisfaction up to the expected duration. Identification and classification of security durability attributes help to improve security during software development. In order to develop durable as well as secure software, the relationship between security and durability characteristics (at different levels) has been determined in the authors' previous work [24]. For using the methodology of Fuzzy AHP, these attributes and sub-attributes are converted into a hierarchy that is shown in figure 3 .

Figure 3: Hierarchy Modeling of Security Durability Attributes

Figure 3 depicts the hierarchical structure of security durability and its attributes which are classified in three levels. At different levels of the hierarchy, the relationship between software quality attributes and software security attributes is shown. Finally, the association of software security attributes with software durability attributes has been shown. An attribute at level 1 affects one or more attributes at the higher level but its effect is not same on them, it may vary. For example, reliability has an impact on dependability, human trust, and trustworthiness as well [33], but its impact values are not same in both levels. Further, the hierarchy of attributes helps to differentiate among the impact of the same attribute to the other attribute at the higher level. Among all the attributes, trustworthiness, human trust, and dependability affect the durability

Peer) Comput. Sci. reviewing PDF | (CS-2019:03:35600:1:2:NEW 14 Jun 2019) 
501 directly but many attributes of security affect durability indirectly as well, for example, availability, 502 etc. For the purpose of estimation of security durability, attributes at level 1 are denoted as C1, 503 C2, and C3. Attributes at level 2 are denoted as C11, C12, C13, C14, C15 for C1 and C21, $504 \mathrm{C} 22 \ldots . . \mathrm{C} 25$ for $\mathrm{C} 2$ and C31, C32....C35 for C3. Attributes at level 3 are denoted as

505

506

507

508

509

510

511

512

513

514

515

516

517

518

519

520

521

522

523

524

525

526

527

528

529

530

531

532

533

534

535

536

537

538

539

540

541

542

543

544

545

C111. .C115 for $\mathrm{C} 11$ and so on which are shown in figure 3.

\section{Construction of Pair-Wise Comparison Matrices}

Many times, the assessment of different attributes usually fails because of the connection of multiple qualitative criteria. Fuzzy AHP is a suitable evaluation technique capable of handling this kind of problem with uncertain inputs. Fuzzy AHP is capable of handling ambiguous judgmental inputs given by the number of experts and questionnaires collected by judgments of experts. It is also capable of converting qualitative inputs into quantitative results, in form of weight, ranking as well as performance. To evaluate the weights of the security durability attributes, pair-wise comparison matrixes are constructed in the form of questionnaires for each set of attributes and data has been collected by distributing questionnaires to 50 academicians and industry persons of various affiliations. 20 valid replies were used in this research to measure the importance of security durability attributes.

The data collected through expert's opinions have been arranged in the form of decision matrices. Eigenvector method has been used for taking expert's views. Also, repeated data and redundancy has been removed using 'data only once' method. Although during calculation, these repetitions have been taken into account as every attribute has a different impact on security durability at different levels of hierarchy. To construct the pair-wise comparison matrices, table 1 shows a scale in the previous section. This scale is a nine-point scale ranging from 1- 9, where a greater value represents higher importance. This scale also helped to convert the numerical values into Triangular Fuzzy Numbers (TFN). TFN's can be obtained for computing the fuzzified values of the linguistic terms from the pair-wise judgment matrix. Further, TFN helps the person in making the decision easily. Hence, TFN is used as the membership function in this work.

\section{Aggregation of Pair-Wise Comparison Matrices}

With the help of table 1 and equations (1-5) given in the mechanism section, authors converted the numerical values into TFN and aggregated these values. For all sets of attributes of the hierarchy, aggregated pair-wise comparison matrices are shown from table 4 to table 14 .

\section{Table 4: Aggregated Fuzzify Pair-Wise Comparison Matrix for the First Level}

Table 4 shows the aggregated fuzzify pair-wise comparison matrix of first level attributes including dependability (C1), trustworthiness (C2) and human trust (C3).

\section{Table 5: Aggregated Fuzzify Pair-Wise Comparison Matrix for C1 of Second Level}

Table 5 shows the aggregated fuzzify pair-wise comparison matrix of second level attributes for dependability including availability (C11), reliability (C12), maintainability (C13), confidentiality (C14) and authentication (C15).

Peer) Comput. Sci. reviewing PDF | (CS-2019:03:35600:1:2:NEW 14 Jun 2019) 
546

547

548

549

550

551

552

553

554

555

556

557

558

559

560

561

562

563

564

565

566

567

568

569

570

571

572

573

574

575

576

577

578

579

580

581

582

583

584

585

586

587

588

589

\section{Table 6: Aggregated Fuzzify Pair-Wise Comparison Matrix for C2 of Second Level}

Table 6 shows the aggregated fuzzify pair-wise comparison matrix of second level attributes for trustworthiness including availability (C21), reliability (C22), maintainability (C23), accountability (C24) and survivability (C25).

\section{Table 7: Aggregated Fuzzify Pair-Wise Comparison Matrix for C3 of Second Level}

Table 7 shows the aggregated fuzzify pair-wise comparison matrix of second level attributes for human trust including reliability (C31), consumer integrity (C32), accountability (C33), confidentiality (C34) and authentication (C35).

Table 8: Aggregated Fuzzify Pair-Wise Comparison Matrix for C11 of Third Level

Table 8 shows the aggregated fuzzify pair-wise comparison matrix of third level attributes for availability (related to dependability) including auditability (C111), feasibility (C112), accessibility (C113), software effectiveness evaluation (C114) and operational controls (C115).

\section{Table 9: Aggregated Fuzzify Pair-Wise Comparison Matrix for the C12 of the Third Level}

Table 9 shows the aggregated fuzzify pair-wise comparison matrix of third level attributes for reliability (related to dependability) including feasibility (C121), time-efficiency (C122), user satisfaction (C123), and business continuity (C124).

\section{Table 10: Aggregated Fuzzify Pair-Wise Comparison Matrix for the C13 of the Third Level}

Table 10 shows the aggregated fuzzify pair-wise comparison matrix of third level attributes for maintainability (related to dependability) including auditability (C131), scalability (C132), traceability (C133), detectability (C134), extensibility (C135), flexibility (C136), accessibility (C137) and time-efficiency (C138).

\section{Table 11: Aggregated Fuzzify Pair-Wise Comparison Matrix for the C14 of the Third Level}

Table 11 shows the aggregated fuzzify pair-wise comparison matrix of third level attributes for confidentiality (related to dependability) including user satisfaction (C141), software effectiveness evaluation (C142) and operational controls (C143).

Table 12: Aggregated Fuzzify Pair-Wise Comparison Matrix for the $\mathbf{C} 15$ of the Third Level 
590

591

592

593

594

595

596

597

598

599

600

601

602

603

604

605

606

607

608

609

610

611

612

613

614

615

616

617

618

619

620

621

622

623

624

625

626

627

628

629

630

631

632

633

Table 12 shows the aggregated fuzzify pair-wise comparison matrix of third level attributes for authentication (related to dependability) including psychological acceptability (C151), user satisfaction (C152), software effectiveness evaluation (C153) and operational controls (C154). Due to repeated attributes in the second level, some set of third level attributes are repeated when the set of attributes considered independently. Hence, aggregated fuzzify pair-wise comparison matrixes of third level attributes for C21, C22, and C23 (related to trustworthiness) are same as $\mathrm{C} 11, \mathrm{C} 12$, and C13, respectively. According to hierarchy, accountability (C24) depends only on software effectiveness evaluation (C241) with respect to security durability. So, there is no need of fuzzify pair-wise comparison matrix. Further, aggregated fuzzify pairwise comparison matrix for the $\mathrm{C} 25$ of the third level is shown in table 13.

\section{Table 13: Aggregated Fuzzify Pair-Wise Comparison Matrix for the C25 of the Third Level}

Table 13 shows the aggregated fuzzify pair-wise comparison matrix of third level attributes for survivability (related to trustworthiness) including detectability (C251), extensibility (C252) and flexibility (C253).

\section{Table 14: Aggregated Fuzzify Pair-Wise Comparison Matrix for the C32 of the Third Level}

Table 14 shows the aggregated fuzzify pair-wise comparison matrix of third level attributes for consumer integrity (related to human trust) including psychological acceptability (C321), user satisfaction (C322), business continuity (C323) and operational controls (C324). Again, aggregated fuzzify pair-wise comparison matrixes of third level attributes for C31, C34, and C35 (related to human trust) are same as C12, C14 and C15, respectively. Further, accountability (C33) depends only on software effectiveness evaluation (C331) with respect to security durability. So, there is no need for fuzzify pair-wise comparison matrix. After the Aggregation of fuzzify pair-wise comparison matrixes, defuzzification process is implemented in the next portion.

\section{Defuzzification and Local Weights}

Now for getting the linguistic values from the aggregated TFN values, the alpha cut method is used for defuzzification process [25]. Alpha Cut method is formulated in equations (6-9) in the previous section.

All aggregated TFN values that are defuzzified have been shown from the table 15 to table 25 . In this work, $\alpha$ and $\beta$ are taken equal to 0.5 . Where $\alpha$ and $\beta$ carry the meaning of preferences and risk tolerance of participants. The values of $\alpha=0.5$ and $\beta=0.5$ indicated that attributes are neither extremely optimistic nor pessimistic about their comparison. Further, variation in results due to the value of $\alpha$ and $\beta$ is discussed in the sensitivity analysis section. After defuzzification of pair-wise matrix, Consistency Ratio (CR) is calculated with the help of equations (14-15) and table 6 as already discussed in the previous section. To continue the Fuzzy AHP analysis, CR must be acceptable. If $C R$ is less than 0.1 , then weights are calculated. Otherwise refined pair-

Peer] Comput. Sci. reviewing PDF | (CS-2019:03:35600:1:2:NEW 14 Jun 2019) 
634

635

636

637

638

639

640

641

642

643

644

645

646

647

648

649

650

651

652

653

654

655

656

657

658

659

660

661

662

663

664

665

666

667

668

669

670

671

672

673

674

675

676

677 wise matrixes are prepared and the process is repeated again. After verification of the $C R$ value, by applying equations (12-13), local weights of security durability attributes are calculated. Table 15 to table 25 depicts the local weights and CR values for each pair-wise comparison matrix. $C R$ is less than 0.1 for all matrices. This $C R$ value is acceptable to continue Fuzzy AHP analysis.

Table 15: Local Weight of Attributes for First Level

Table 16: Local Weight of Attributes for C1 of Second Level

Table 17: Local Weight of Attributes for C2 of Second Level

Table 18: Local Weight of Attributes for C3 of Second Level

Table 19: Local Weight of Attributes for C11 of the Third Level

Table 20: Local Weight of Attributes for C12 of the Third Level

Table 21: Local Weight of Attributes for C13 of the Third Level

Table 22: Local Weight of Attributes for C14 of the Third Level

Table 23: Local Weight of Attributes for C15 of the Third Level

Table 24: Local Weight of Attributes for C25 of the Third Level

Table 25: Local Weight of Attributes for C32 of the Third Level

A local weight shows the level-wise impact of these attributes and is also called independent weight. To evaluate the weights of the security durability attributes throughout the hierarchy, final weights have been calculated in the next portion.

Final Weights of Each Attribute

Final weights are also called dependent weights of security durability throughout the hierarchy. The final weights (dependent weights) of each attribute through hierarchy are shown in Table 26.

\section{Table 26: The Final Weights of Each Criterion through Hierarchy}

The hierarchical structure related to security durability attributes is helpful in building the effective security design of software. The decomposition of security durability attributes has been considered in three levels viz., level 1, level 2 and level 3. Based on the results, the rank of each attribute is obtained at level 1,2 and 3. 
678

679

680

681

682

683

684

685

686

687

688

689

690

691

692

693

694

695

696

697

698

699

700

701

702

703

704

705

706

707

708

709

710

711

712

713

714

715

716

717

718

719

720

On the basis of final weights, evaluation of the ranks of each attribute for improving security durability/security life span of software is illustrated. The required security durability attributes are extracted from figure 3 and table 26 shows the importance of each attribute throughout the hierarchy in the form of priorities. Repeated attributes of level 2 and level 3 are removed and figure 4 and figure 5 show the final priorities of security durability attributes at level 2 and level 3.

Figure 4: Second level Attributes without Repetition

Figure 5: Third Level Attributes without Repetition

Figure 4 and figure 5 show the final priorities of security durability attributes at level 2 and level 3 after removing the repeated attributes. These priorities will help towards creating the development suggestions/guidelines.

\section{Procedure for Improving Security Durability of Software}

The purpose of this research work is to enhance the security durability of software based on the suggestions and guidelines proposed by the authors. The suggestions or guidelines inferred from the assessment will surely help the developers to improve the security durability of software during its development. To produce any guidelines for developers related to design, it is important to consider properties of the design.

Object-oriented design properties are measured using its corresponding security metrics [25]. Further, object-oriented security metrics are useless if they are not mapped to security durability parameters. There are numerous security metric suites available to predict security of the software namely Vulnerable Association of an Object-Oriented Design(VA_OOD) [35], Security Requirements Statistics (SRs) [36], Number of Design stage Security Errors (NDSE) [37], Critical Class Coupling (CCC) [38], Critical Class Extensibility(CCE) [39], Critical Super Class Propagation(CSP) [35], Classified Method Inheritance (CMI) [40], Classified Attributes Inheritance (CAI) [36], Critical Design Propagation (CDP) [38], Classified Instance Data Accessibility (CIDA) [39], Classified Methods Weight (CMW) and many more [40]. The names specified above are security metrics for the design phase. These metrics are specifically used for measuring the impact of the properties. For example, to measure the coupling of classes, Critical Class Coupling (CCC) is used by most of the practitioners [40].

Most of the design properties have positive impact on security attributes including serviceoriented design and object-oriented design, etc. [37]. On the other hand, each design strategy has its own positive and negative impacts on security services of software. In this work, researchers suggest only eight security metrics to developers that may be helpful for measuring and achieving the priorities of third level factors including Critical Class Coupling (CCC), Critical Class Extensibility (CCE), Critical Super Class Propagation (CSP), Classified Method Inheritance (CMI), Classified Attributes Inheritance (CAI), Critical Design Propagation (CDP), Classified Instance Data Accessibility (CIDA) and Classified Methods Weight (CMW).

Peer] Comput. Sci. reviewing PDF | (CS-2019:03:35600:1:2:NEW 14 Jun 2019) 
721

722

723

724

725

726

727

728

729

730

731

732

733

734

735

736

737

738

739

740

741

742

743

744

745

746

747

748

749

750

751

752

753

754

755

756

757

758

759

760

761

762

763

764

765

766

767

768
Through the impact of third level priorities, second level, first level, and overall security durability are measured and achieved. Security durability attributes (third level) affect many design attributes and impact of these attributes may be helpful for assessment through suggested security metrics as:

- Auditability affects design properties such as reusability [33], discoverability [34], design by contract [35] and design size [34]. With the help of CMI and CAI metrics, affected design properties of auditability may be measured and improved [36]. Further, CMI measures the ratio between a number of classified methods and the total number of classified methods and CAl measures the ratio between numbers of classified attributes and the total number of classified attributes.

- Scalability affects design properties such as coupling [33] and reusability [34]. With the help of CCC and CMI metrics, affected design properties of scalability may be measured and improved [39]. Further, CCC helps to measure the ratio between the numbers of all classes linked with classified attributes.

- Feasibility affects design properties such as reusability [40] and discoverability [39]. With the help of CAI and CMI metrics, affected design properties of feasibility may be measured and improved.

- Traceability affects design properties such as coupling 34], abstraction [40] and discoverability [61]. With the help of CCC and CSP metrics, affected design properties of traceability may be measured and improved [40]. Further, CSP helps to measure the ratio between the numbers of critical super classes and a total number of critical classes in an inheritance hierarchy; and also helps to implement the abstraction.

- Detectability affects design properties such as autonomy 35], discoverability [36] and cohesion [60]. With the help of CCE metric, affected design properties of detectability may be measured and improved [36]. Further, CCE helps to measure the ratio between numbers of non-finalized classes in design with the critical classes in that design.

- Accessibility affects design properties such as complexity [37] and design size [38]. With the help of CDP and CIDA metrics, affected design properties of accessibility may be measured and improved [39]. Further, CDP measures the ratio between the number of critical classes and a total number of classes in design and measures the impact of the size of a certain design on security. CIDA is helpful to measure the ratio between the number of classified instance public attributes and a total number of classified attributes in a class. It also measures the impact of the size of a certain design on security.

- Time-efficiency affects design properties such as design size [35] and reusability [36]. With the help of CMI and CAI metrics, affected design properties of time-efficiency may be measured and improved.

- Extensibility affects design properties such as complexity [34] and reusability [38]. With the help of $\mathrm{CMI}$ and CAl metrics, affected design properties of extensibility may be measured and improved.

- Psychological acceptability affects design properties such as abstraction [39], design by contract [32] and cohesion [34]. With the help of CSP metric, affected design properties of psychological acceptability may be measured and improved.

- User satisfaction affects design properties such as abstraction [40] and autonomy [39]. With the help of CSP and CCE metrics, affected design properties of user satisfaction may be measured and improved.

- Software effectiveness evaluation affects design properties such as abstraction [34] and coupling [36]. With the help of CCE, CMI, CAI and CSP metrics, affected design properties of software effectiveness evaluation may be measured and improved. 
769

770

771

772

773

774

775

776

777

778

779

780

781

782

783

784

785

786

787

788

789

790

791

792

793

794

795

796

797

798

799

800

801

802

803

804

805

806

807

808

809

810

811

- Business continuity affects design properties such as coupling and cohesion [35]. With the help of CCC and CMW metrics, affected design properties of business continuity may be measured and improved.

- Flexibility affects design properties such as coupling [37] and statelessness [38]. With the help of CMW, CDP, and CCC metrics affected design properties of flexibility may be measured and improved [39]. Further, CMW helps to measure the ratio between the numbers of classified methods and a total number of methods in a given class. CDP measures the ratio between the number of critical classes and a total number of classes, and also helps to measure the impact of the size of a certain design on security.

- Also, operational controls affect design properties such as coupling [33] and statelessness [35]. With the help of CMW, CDP, and CCC metrics affected design properties of operational controls may be measured and improved.

Through the measurement of third level attributes, the impact of second level attributes of security durability may be measured. Further, to measure and improve the impact of second level attributes, the following are the referrals:-

- Confidentiality is affected by third level attributes including user satisfaction, software effective evaluation, and operational controls. With the help of the metrics of design properties for these attributes, the impact of confidentiality may be measured and improved.

- Authentication is affected by third level attributes including psychological acceptability, user satisfaction, software effectiveness evaluation, and operational controls. With the help of the metrics of design properties for these attributes, the impact of authentication may be measured and improved.

- Reliability is affected by third level attributes including feasibility, time-efficiency, user satisfaction, and business continuity. With the help of the metrics of design properties for these attributes, the impact of reliability may be measured and improved.

- Survivability is affected by third level attributes including detectability, extensibility, and flexibility. With the help of the metrics of design properties for these attributes, the impact of survivability may be measured and improved.

Through the measurement of second level attributes, the impact of first level attributes of security durability may be measured. Further, to measure and improve the impact of first level attributes, the following are the referrals:-

- Dependability is affected by second level attributes including availability, reliability, maintainability, confidentiality, and authentication. With the help of the impact of these second level attributes, the impact of dependability may be measured and improved.

- Trustworthiness is affected by second level attributes including availability, reliability, maintainability, accountability, and survivability. With the help of the impact of these second level attributes, the impact of trustworthiness may be measured and improved.

- Human trust is affected by second level attributes including reliability, consumer integrity, accountability, confidentiality, and authentication. With the help of the impact of these second level attributes, the impact of human trust may be measured and improved.

With the help of given final priorities of level 1,2 and 3 and above discussion, developers should focus on enhancing the high prioritized attributes. Measurement through the metrics is necessary for enhancing the impact of these attributes on overall security durability of software

Peer] Comput. Sci. reviewing PDF | (CS-2019:03:35600:1:2:NEW 14 Jun 2019) 
812 services. Further, recommendations for better implementation and improvement are

813 descriptively given below:

814 - Improve security durability awareness among developers by adequate education and training

815

816

817

818

819

820

821

822

823

824

825

826

827

828

829

830

831

832 to achieve sound security durability culture in the organizational environment during the use of software services.

- The economic aspect of security life span should be clearly understood and addressed as one of the important factors for the organization in the recent information era.

- Periodically review the performance of security durability policy implementations using the MCDM techniques because these techniques hail from academia as well as the software industry so as to realize the real-world practices.

- The development guidelines that have a positive effect on the highest priority security durability attribute, which in this case, dependability, must be gathered.

- On the basis of assessment, security metric for dependability should be prepared and calculated

- Focus at dependability, human trust and trustworthiness which are important factors for the security durability of software services.

- Importance of level 1, level 2 and level 3 attributes must be followed by developers.

- In level 2, confidentiality, authentication, and reliability are more desirable attributes and necessary attributes amongst all the other attributes of security durability.

- In level 3, operational controls, software effectiveness evaluation, and feasibility are more essential and required attribute amongst all the other attributes of security durability.

833

834

835

836

837

838

839

840

To analyze the impact of given priorities, suggestions and recommendations, researchers evaluated the performance of security durability in both subjective and objective perspectives. Further, subjective assessment has been done in the previous portion of this section. To evaluate the objective assessment, this work is taking two alternatives of BBAU software, i.e., version 1 and version 2 . The process is discussed in the next portion.

\section{Ratings of Attributes}

841

A rating is the evaluation of something, in terms of quality, quantity, or some combination of both.

842 According to Oxford dictionary "Rating is a classification of something based on a comparative

843 assessment of their quality, standard, or performance" [41].

844 To evaluate the objective weights, researchers have taken the ratings of security durability 845 attributes from the development team for BBAU software including version 1 and version 2 . Old 846 design of the software is called version 1 and modified design of the software is called version 2. 847 According to the given priorities and recommendations, the suggested metrics will be helpful in 848 modifying the design.

849 The suggested metrics may be helpful in achieving the priorities attained and reform the security 850 design of software. To measure the impact of security durability attributes for version 1 and 851 version 2, authors converted the linguistic values into numerical values with the help of rating 852 scale table 2 and fuzzy aggregation method was used to evaluate the ratings (also called 853 objective weights). Further, the fuzzy aggregation method was enlisted in various research areas 854 for decision making, rating and so on [33-34]. The next portion discusses fuzzifying and aggregate 855 of the ratings.

856 
857

858

859

860

861

862

863

864

865

866

867

868

869

870

871

872

873

874

875

876

877

878

879

880

881

882

883

884

885

886

887

888

889

890

891

892

893

894

895

896

897

898

899

900

Fuzzified Average Ratings

Ratings of security durability attributes are collected at level 1 , level 2 and level 3 . With the help of rating scale table 2, linguistic values were converted into numerical values and numerical values into Triangular Fuzzy Numbers (TFN). To confine the vagueness of the parameters, which are related to alternatives, TFN is used [26]. With the help of equations (1,3-5), fuzzified average ratings are evaluated. Table 27 shows the fuzzified average ratings of security durability attributes for version 1 and version 2.

\section{Table 27: Fuzzified Average Ratings}

Table 27 shows the fuzzified average ratings of security durability attributes (attributes of level 1 , level 2 and level 3) for version 1 and version 2. Local ratings of security durability attribute for version 1 and version 2 has been evaluated in the next portion.

\section{Defuzzification and Local Ratings}

With the help of equations (7-9), local ratings of security durability attributes are estimated. These local ratings are also called independent ratings. Further, table 28 maps the local ratings for version 1 and version 2 .

\section{Table 28: Local Rating of the Attributes for Level 1, 2 and 3}

Table 28 shows the local ratings of security durability attributes for level 1, level 2 and level 3 , respectively. Further, local ratings profile the level-wise impact of these attributes for version 1 and version 2 and are also called independent ratings. To evaluate the impact of the security durability attributes throughout the hierarchy, final ratings are calculated in next portion.

\section{Final Rating of Each Attribute}

Table 28 above shows the independent ratings of every attribute at level 1, 2 and 3 . Next step in this row is to calculate the final ratings of attributes according to their place in the hierarchy. For calculating the final ratings, the lower level ratings are multiplied to the higher level ratings. Table 29 shows the final ratings of each attribute through the fuzzy method.

\section{Table 29: Final Ratings of Each Attribute}

Many attributes at level 2 and level 3 are repeated but their impact on its higher level attributes is different. With the help of hierarchy, dependent ratings are evaluated but there are different impacts of the same attribute. With the help of final ratings and weights, security durability of software is estimated for version 1 and version 2 in the next portion.

\section{Results}


901

902

903

904

905

906

907

908

909

910

911

912

913

914

915

916

917

918

919

920

921

922

923

924

925

926

927

928

929

930

931

932

933

934

935

936

937

938

939

940

941

942

943

944

\section{Assessment of Security Durability}

From equation (16), security durability is assessed for two alternatives, i.e., version 1 and version 2 with the help of final ratings $\left(R_{i}\right)$ and weights $\left(W_{i}\right)$ of attributes. Overall security durability is shown in table 30 .

Table 30: Overall Security Durability

\section{Figure 6: Graphical representation of Overall Security Durability}

Table 30 and figure 6 are showing the values of security durability of BBAU software. Value of security durability for the old version (version 1 ) is 0.2852 and value of security durability for modified version (version 2 ) is 0.4700 . Again, with the help of final weights, final ratings of both version and equation 16, the impact of security durability at first level are calculated which is shown in table 31 .

\section{Table 31: Security Durability Impact at Level 1}

\section{Figure 7: Graphical representation of Security Durability Impact at Level 1}

Table 31 and figure 7 are showing the values of security durability on first level attributes. Again, with the help of final weights, final ratings of both version and equation 16, the impact of security durability at the second level are calculated which is shown in table 32.

Table 32: Security Durability Impact at Level 2

\section{Figure 8: Graphical representation of Security Durability Impact at Level 2}

Table 32 and figure 8 enlist the values of security durability on second level attributes. Again, with the help of final weights, final ratings of both version and equation 16, the impact of security durability at third level are calculated which has been presented in table 33 .

Table 33: Security Durability Impact at Level 3

Figure 9: Graphical representation of Security Durability Impact at Level 3

Table 33 and Figure 9 are showing the values of security durability on third level attributes.

Sensitivity Analysis of the Results

The technique used to determine how independent variable values will impact a particular dependent variable under a given set of assumptions is defined as sensitivity analysis [67]. Sensitivity analysis also focuses on analyzing the effects of changes in key values of the project and depends upon one or more input variables within the specific boundaries.

Peer] Comput. Sci. reviewing PDF | (CS-2019:03:35600:1:2:NEW 14 Jun 2019) 
945

946

947

948

949

950

951

952

953

954

955

956

957

958

959

960

961

962

963

964

965

966

967

968

969

970

971

972

973

974

975

976

977

978

979

980

981

982

983

984

985

986

987

988

Authors have taken the values of $\alpha$ and $\beta$ as 0.5 and 0.5 , respectively, during the defuzzification. The range of these two values ranges between 0 and 1 , in such a way that a lesser value indicates greater uncertainty in decision making to preferences and risk tolerance of the participants. 0.5 value for $\alpha$ and $\beta$ is used to represent a balanced environment because the values of $\alpha$ and $\beta$ are dependent on environmental uncertainties. This indicates that participants are neither extremely optimistic nor pessimistic about their judgments. These values will directly affect the weights of individual criteria, priority ranking and overall assessment of security durability.

If the participants involved in priority assessment have strong background knowledge of software security, the values of $\alpha$ and $\beta$ can be readjusted to indicate confident judgments. Further, the sets of $\alpha$ and $\beta$ values are 81 (9x9) including $(0.1,0.1),(0.1,0.2),(0.2,0.1)$, $(0.1,0.3),(0.3,0.1)$ etc. The accuracy of Fuzzy AHP can be further improved by investigating the impact of $\alpha$ and $\beta$ values on the final results and analysis is needed in order to determine the values of $\alpha$ and $\beta$ truthfully. That's why, to check the variations in the results, authors have used ten combinations of $\alpha$ and $\beta$ values for version 1 and version 2 as experiment including E1 $(0.1,0.1)$, E2 $(0.5,0.1)$, E3 $(0.5,0.3)$, E4 $(0.5,0.7)$, E5 $(0.5,0.9), \mathrm{E} 6(0.1,0.5), \mathrm{E} 7(0.3,0.5)$, E8 $(0.7,0.5), \mathrm{E} 9(0.9,0.5), \mathrm{E} 10(0.9,0.9)$ with E0 $(0.5,0.5)$. Further, the value of $\alpha$ is constant for E2, E3, E4, E5, and value of $\beta$ is in variation. While, the value of $\beta$ is constant for E6, E7, E8, E9, and value of $\alpha$ is in variation. The results are shown in table 34 .

\section{Table 34: Sensitivity Analysis Due to $\alpha$ and $\beta$ Values}

\section{Figure 10: Graphical Representation of Sensitivity Analysis}

Table 34 and Figure 10 show the variation in results due to $\alpha$ and $\beta$ values. Although, E0 (0.5, 0.5 ) gives the concentrated values of security durability including $0.2852,0.4700$ for version 1 and version 2 , respectively. The results through the values of $\alpha$ and $\beta$ (as 0.5 ) indicate that a balanced environment about expert's judgments may give the best results. After going through the results of sensitivity analysis it has been determined that variation in the values of overall security durability is not negligible. Preferences of participants and risk tolerance of participants do have a considerable impact on the value of security durability.

\section{Discussion}

A series of tragedies and chaos caused by the insecure software proves that the duration of software security may become a grave matter of life and death at the time. Software industries are now focusing on longer security services of software as a major concern. Software security measurement and improvement have been one of the most talked about topics in organizations. In addition, identifying and addressing various security attributes during software development may reduce maintenance time and costs incurred. Security durability may be considered as one of the supporting attributes of security. Because durability strengthens the fact that longer security doesn't need maintenance for a specific duration. This decreases the cost and time 
989 invested in maintenance. Security durability assessment may intensely influence the security of 990 the software.

991 The investigation of security durability parameters and their effect on security will ease to reveal 992 the qualities and shortcomings of the security strength. The precise estimation of security 993 durability remains a vital issue in light of the fact that there is supposedly no great comprehension 994 of the idea of security durability. There is no unmistakable definition to 'what perspectives are 995 identified with security durability'. Finding an appropriate method to measure security durability and the greater part of the angles identified with it is exceptionally troublesome. Hence, an examination of security durability assessment remains vital for security developers, programming engineers, and their clients. Durability applies a methodology that conveys robust, vibrant security to support, facilitate all business initiatives, including clouds, mobility, and improve security. The main advantages of security durability assessment are given below:

- Improved probability of lifetime of security software

1003

- Reduced cost of maintenance on security development life cycle

- Reduced maintenance and repair costs of software security

- Improved satisfaction of user's and market value of the product

- Prioritized security durability attributes and guidelines may be helpful in designing secure as well as durable software

- Field of security is still in its infancy and only quantitative assessment of security durability may facilitate the mechanism on predicting how long the software is secured.

- Since quantitative assessment techniques for security durability are not available, the security community primarily uses qualitative assessment techniques for security. The proposed study may help industry professionals in producing a quantitative estimation of security durability.

A consistent quantitative estimate of security durability is highly desirable for secure software during the development life cycle. The literature survey reveals that nothing significant, precise and clear exists in this regard that can be used to quantify security durability in the early stage of development. Therefore, in absence of any framework or model for quantifying security durability, it is worthwhile to develop a methodology for security durability quantification. The main aim of this research is to gain an in-depth understanding of the durable security/security durability concept and the need to design durable as well as secure software.

Every coin has two sides. From the research point of view both surfaces hold imperative positions and are tenable. However, the positive appearance offers new dimensions to the proposed study while the negative portion highlights the deficiencies of work. After resolving the deficiencies of the intended work, the redesigned efforts ascertain innovative features of lessons. Despite having so many reasons favorable for the industrial adaptation of the approach, there are negative aspects also. Some are listed as follows:

- The approach is assessed with only twenty experts. The expert group may be larger for big datasets. Small group of experts may negotiate with the results.

- Due to unavailability of big industry data, the proposed framework is only validated with a small set of data which may further affect the overall results.

- The approach has used security metrics for improvement which has been derived from previous work. A specific security metric for security durability assessment can be developed. 
1035

1036

1037

1038

1039

1040

1041

1042

1043

1044

1045

1046

1047

1048

1049

1050

1051

1052

1053

1054

1055

1056

1057

1058

1059

1060

1061

1062

1063

1064

1065

1066

1067

1068

1069

1070

1071

1072

1073

1074

1075

1076

1077

1078

1079

1080

1081

1082

- To provide more attention on security durability quantification area, only a set of security attributes and durability attributes have been chosen from the various security attributes and durability attributes, respectively. There can be more specific attributes of security durability and they may be integrated later for better results.

\section{Conclusion}

The software security area of software engineering has been largely ignored since the birth of software. There may be several reasons for this. There was an era in which software security was an easy task and was achieved by applying only some passwords or installing some software. As the time passed, complex antivirus software has replaced easy-to-install software. The multiple connections making a policy of computer make it vulnerable to any virus and thus making it insecure for handling personal and sensitive information. Though there has been lot of work done in the field of software security to achieve maximum security in less time and cost, security also needs maintenance. The cost and time incurred on maintenance are increasing day by day. To reduce the maintenance time and cost and to improve the security life span of software, estimation of security durability will help in minimizing time and cost on the maintenance for a specific time period. On the successful completion of the study, the researchers found that early security durability estimation is highly desirable in the area of secure software development.

\section{Acknowledgements}

Authors are thankful to College of Computer and Information Sciences, Prince Sultan University for providing the funds for this research endeavour.

\section{References}

1) Tekinerdogan B., Sozer H., Aksit M., (2008), Software Architecture Reliability Analysis using Failure Scenarios, Journal of Systems and Software, Volume 81, Issue 4, pp. 558-575.

2) Subashini S., Kavitha V., (2011), A Survey on Security Issues in Service Delivery Models of Cloud Computing, Journal of Network and Computer Applications, Volume 34, Issue 1, pp. 1-11.

3) Boegh J., (2008), A New Standard for Quality Requirements, IEEE Software, Volume 2, pp. 57-63.

4) 2019 Cybersecurity Trends: 31 Experts Make Predictions (2018), Available at: https://phoenixnap.com/blog/cybersecurity-experts-threats-trends Last Visit on 19 Feb 2019.

5) SaaS Industry Market Report: Key Global Trends \& Growth Forecasts (2018), Available at: https://financesonline.com/2018-saas-industry-market-report-key-global-trends-growth-forecasts/ Last Visit on 04 Sep 2018.

6) New Data: Software as a Service Industry Revenue up 23\% This Year as Shift to the Cloud Continues (2017), Available at: https://www.geekwire.com/2017/new-data-software-service-industry-revenue-23year-shift-cloud-continues/ Last Visit on 05 Sep 2018.

7) CA Veracode Report (2018), Available at: https://techbeacon.com/sorry-state-software-security-securedevelopment-key, Last Visit Oct 222018.

8) Dalton M., Kannan H., Kozyrakis C., (2007), Raksha: A Flexible Information Flow Architecture for Software Security, ACM SIGARCH Computer Architecture News, Volume 35, Issue 2, pp. 482-493.

9) Gray, D., Allen, J., Cois, C., Connell, A., Ebel, E., Gulley, W.,Wisniewski, B. D. (2015), Improving Federal Cyber Security Governance through Data Driven Decision Making and Execution, Technical Report - CMU/SEI-2015-TR-011, Software Engineering Institute, Carnegie Mellon University United States.

10) Mikhailov L., (2003), Deriving Priorities from Fuzzy Pairwise Comparison Judgments, Fuzzy Sets and Systems, Volume 134, Issue 3, pp. 365-385.

Peer] Comput. Sci. reviewing PDF | (CS-2019:03:35600:1:2:NEW 14 Jun 2019) 
1083

1084

1085

1086

1087

1088

1089

1090

1091

1092

1093

1094

1095

1096

1097

1098

1099

1100

1101

1102

1103

1104

1105

1106

1107

1108

1109

1110

1111

1112

1113

1114

1115

1116

1117

1118

1119

1120

1121

1122

1123

1124

1125

1126

1127

1128

1129

1130

1131

1132

1133

1134

1135

1136

1137

1138
11) Hahn W. J., Seaman S. L., Bikel R., (2012), Making Decisions With Multiple Attributes: A Case In Sustainability Planning, Graziadio Business Review, Volume 15, Issue 2, pp. 365-381.

12) Durable Cost Savings in Government IT, (2016), Available at: https://fcw.com/articles/2016/04/22/costsavings-oped.aspx, Last Visit Oct 202018.

13) Mougouei D., (2017), PAPS: A Scalable Framework for Prioritization and Partial Selection of Security Requirements, Cornell University Library, Publication Number - eprintarXiv: 170600166.

14) Weir C., Becker I., Noble J., Blair L., Aasse M., Rashid A., (2019), Interventions for Software Security, Available at: http://eprints.lancs.ac.uk/131282/1/WeirSEIP2019CameraReady.pdfLast Visit Feb 21 2019.

15) Dayanandan U., Kalimuthu V., (2018) Software Architectural Quality Assessment Model for Security Analysis Using Fuzzy Analytical Hierarchy Process (FAHP) Method, 3D Research, Volume 9 Issue 3, pp. 1-10.

16) Praus F., Kastner W., Palensky P., (2016), Software Security Requirements in Building Automation, Sicherheit 2016 - Sicherheit, Schutz und Zuverlässigkeit, pp. 217-228.

17) Chen C., Alfayez R., Srisopha K., Boehm B., Shi L., (2017), Why is It Important to Measure Maintainability and What are the Best Ways to Do It?", In Proceedings of the 39th International Conference on Software Engineering Companion, IEEE Press, pp. 377-378.

18) Alarifi A., Alsaleh M., Alomar N., (2017), A Model for Evaluating the Security and Usability of eBanking Platforms, Computing, Volume 99, Issue 5, pp. 519-535.

19) Kelty C., Erickson S., (2015), The Durability of Software, Meson Press, Germany, Volume 1, Issue 5, pp. 1-13.

20) Security Awareness Program Special Interest Group PCl Security Standards Council, (2014), Information Supplement: Best Practices for Implementing a Security Awareness Program, PCl Data Security Standard, Version 1.

21) Ensmenger N., (2014), When Good Software Goes Bad: The Surprising Durability of an Ephemeral Technology. In MICE (Mistakes, Ignorance, Contingency, and Error) Conference. Munich, pp.1-16.

22) Parker D. B., (1992), Restating the Foundation of Information Security, Proceedings of the Eighth International Conference on Information Security, Netherlands, pp.139-151.

23) Cusick J. J., (2013), Durable Ideas in Software Engineering: Concepts, Methods and Approaches from My Virtual Toolbox, Bentham Science Publishers.

24) Kumar R., Khan S. A., Khan R. A., (2015), Revisiting Software Security: Durability Perspective, International Journal of Hybrid Information Technology (SERSC), Volume 8, Issue 2, pp.311-322.

25) Goli D., (2013), Group Fuzzy TOPSIS Methodology in Computer Security Software Selection, International Journal of Fuzzy Logic Systems, Volume 3, Issue 2, pp. 29-47.

26) Chong C. Y., Lee S. P., Ling T. C., (2014), Prioritizing and Fulfilling Quality Attributes for Virtual Lab Development through Application of Fuzzy Analytic Hierarchy Process and Software Development Guidelines, Malaysian Journal of Computer Science, Volume 27, Issue 1, pp. 1-19.

27) Saaty T. L., (1995), Transport Planning with Multiple Criteria: The Analytic Hierarchy Process Applications and Progress Review, Journal of Advanced Transportation, Volume 29, Issue 1, pp. 81126.

28) Zadeh L.A., (1965), Fuzzy Sets, Information and Control, Volume 8, Issue 3, pp. 338-353.

29) Csutora R., Buckley J. J., (2001), Fuzzy Hierarchical Analysis: The Lambda-Max Method, Fuzzy Sets and Systems, pp. 181-195.

30) Chang C. W., Wu C. R., Lin H. L., (2008), Integrating Fuzzy Theory and Hierarchy Concepts to Evaluate Software Quality, Software Quality Journal, Volume 16, Number 2, pp. 263-276.

31) Hoehl M., (2013), Framework for Building a Comprehensive Enterprise Security Patch Management Program, STI Graduate Student Research, SANS.

32) Sommardahl B, Durable Software, (2013) Awkward Coder Learning to Behave in Public, pp. 5-8.

33) Rajeev Kumar, Mohammad Zarour, Mamdouh Alenezi, Alka Agrawal, Raees Ahmad Khan, (2019), Measuring Security Durability of Software through Fuzzy-Based Decision-Making Process, International Journal of Computational Intelligence Systems, May 2019.

34) Baas S. M., Kwakernaak H., (1977), Rating and Ranking of Multiple - Aspect Alternatives Using Fuzzy Sets, Automatica, Volume 13, Number 1, pp.47-58.

35) Chowdhury I., Zulkernine M., (2010), Can Complexity, Coupling, and Cohesion Metrics be Used as Early Indicators of Vulnerabilities?, In Proceedings of the 2010 ACM Symposium on Applied Computing, pp. 1963-1969.

Peer) Comput. Sci. reviewing PDF | (CS-2019:03:35600:1:2:NEW 14 Jun 2019) 
1139 36) Abbadi Z., (2011), Security Metrics What Can We Measure?, In Open Web Application Security Project (OWASP), Nova Chapter Meeting Presentation on Security Metrics, Volume 2.

37) Siddiqui S. T., (2017), Significance of Security Metrics in Secure Software Development, International Journal of Applied Information Systems, Volume 12, Issue 6, pp. 10-15.

1143 38) Yadav S., Sunil S., Uttpal S., (2014), A Review of Object-Oriented Coupling and Cohesion Metrics, International Journal of Computer Science Trends and Technology, Volume 2, Issue 5, pp. 45-55.

39) Mohammed O. S., Taha D. B., (2016), Conducting Multi-Class Security Metrics from Enterprise Architect Class Diagram, International Journal of Computer Science and Information Security, Volume 14, Issue 4, pp. 56.

1149 40) Alshammari B. M., (2011), Quality Metrics for Assessing Security Critical Computer Programs, PhD Thesis, Queensland University of Technology.
41) Rating
Definition
by
Oxford
Dictionaries,
(2018),
Available
at: https://en.oxforddictionaries.com/definition/rating, Last Visit Oct 252018. 


\section{Figure 1}

Flow Chart of the Implementation through Fuzzy AHP Method 


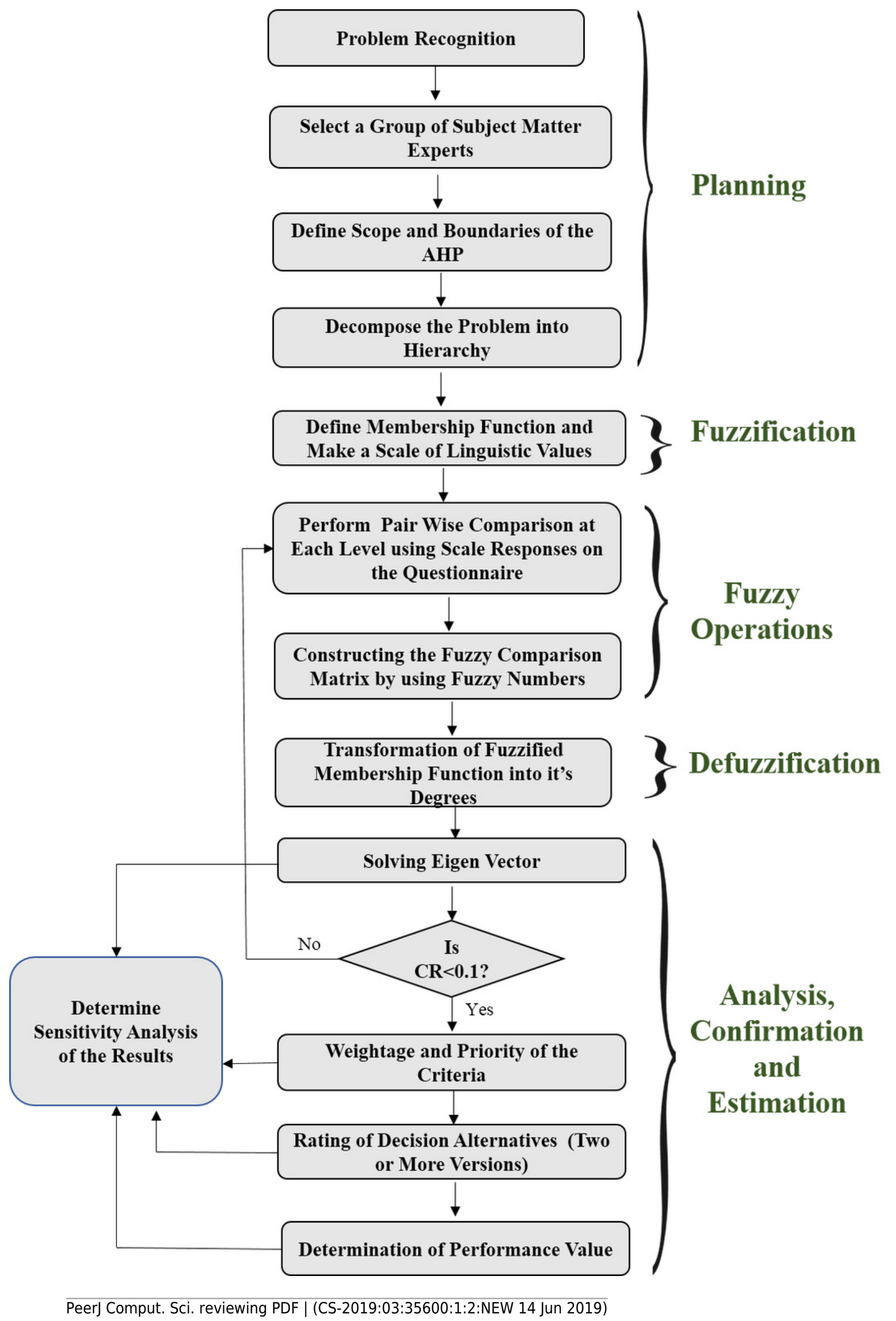


Figure 2

\section{Triangular Fuzzy Number}

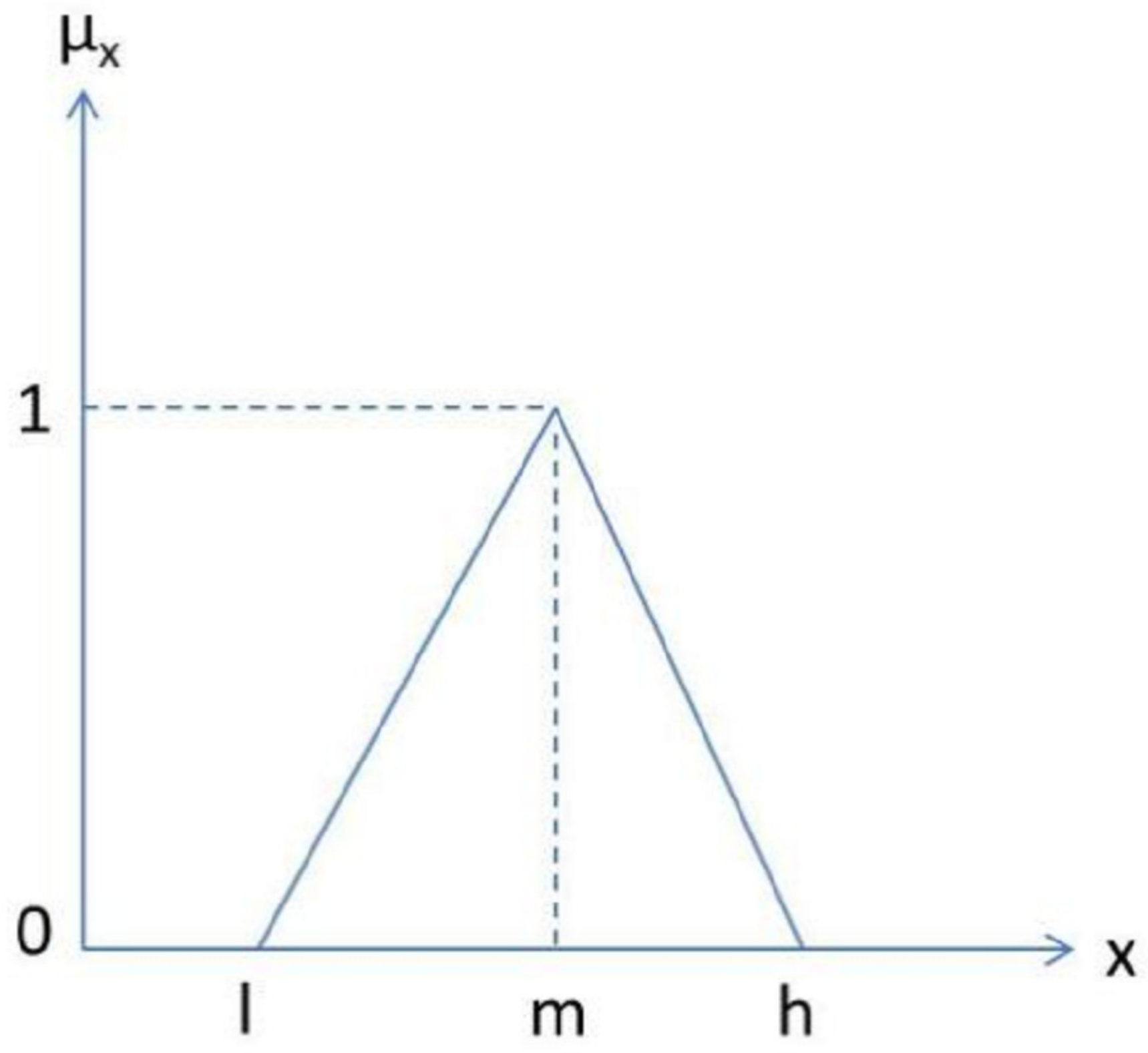




\section{Figure 3}

\section{Hierarchy Modeling of Security Durability Attributes}

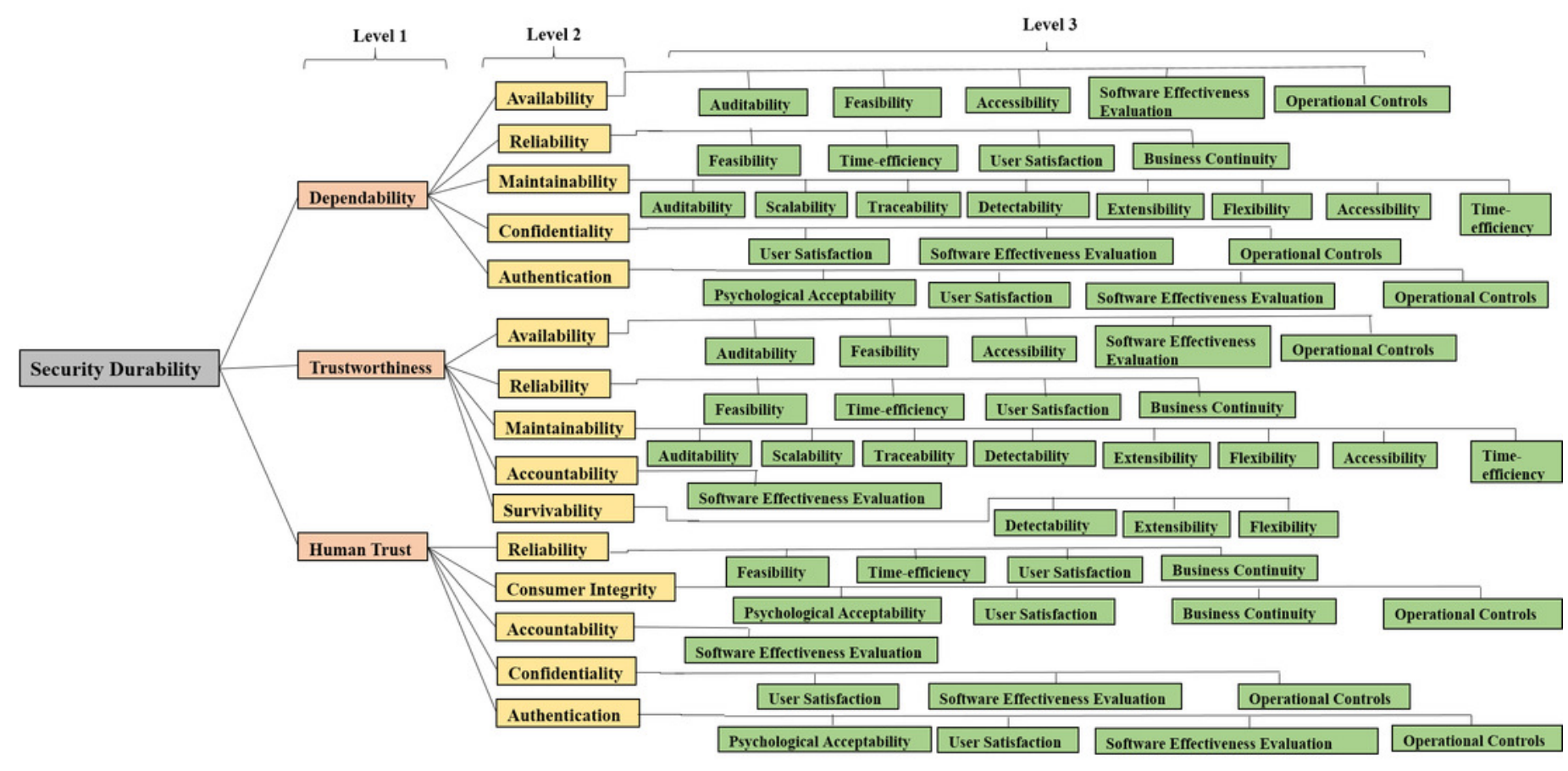




\section{Figure 4}

\section{Second level Attributes without Repetition}

\begin{tabular}{|l|l|l|}
\hline $\begin{array}{l}\text { Second Level } \\
\text { Characteristics }\end{array}$ & $\begin{array}{l}\text { The final } \\
\text { weight of } \\
\text { the second } \\
\text { level }\end{array}$ & $\begin{array}{l}\text { Final } \\
\text { Ranks } \\
\text { of the } \\
\text { Second } \\
\text { Level }\end{array}$ \\
\hline Availability & 0.046 & 10 \\
\hline Reliability & 0.112 & 3 \\
\hline Maintainability & 0.058 & 7 \\
\hline Confidentiality & 0.157 & 1 \\
\hline Authentication & 0.114 & 2 \\
\hline Availability & 0.042 & 12 \\
\hline Reliability & 0.046 & 11 \\
\hline Maintainability & 0.040 & 13 \\
\hline Accountability & 0.060 & 6 \\
\hline Survivability & 0.083 & 4 \\
\hline Reliability & 0.054 & 8 \\
\hline Consumer Integrity & 0.039 & 14 \\
\hline Accountability & 0.035 & 15 \\
\hline Confidentiality & 0.052 & 9 \\
\hline Authentication & 0.064 & 5 \\
\hline
\end{tabular}

Set of Attributes without Repetition

\begin{tabular}{|c|c|}
\hline Priority & Characteristics of Level 2 \\
\hline 1 & Confidentiality \\
\hline 2 & Authentication \\
\hline 3 & Reliability \\
\hline 4 & Survivability \\
\hline 5 & Accountability \\
\hline 6 & Maintainability \\
\hline 7 & Availability \\
\hline 8 & Consumer Integrity \\
\hline
\end{tabular}


Figure 5

\section{Third Level Attributes without Repetition}

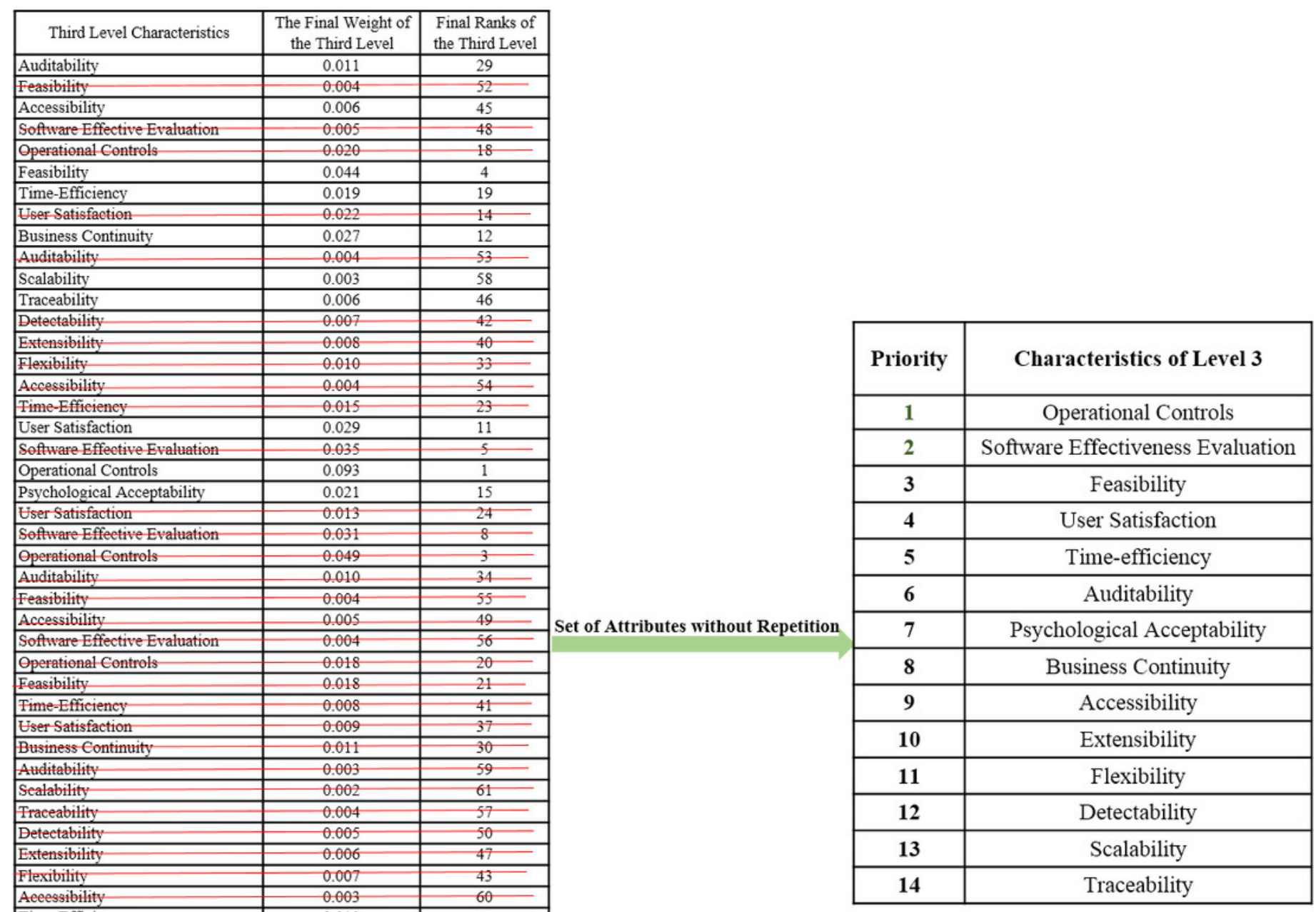


Figure 6

Graphical representation of Overall Security Durability

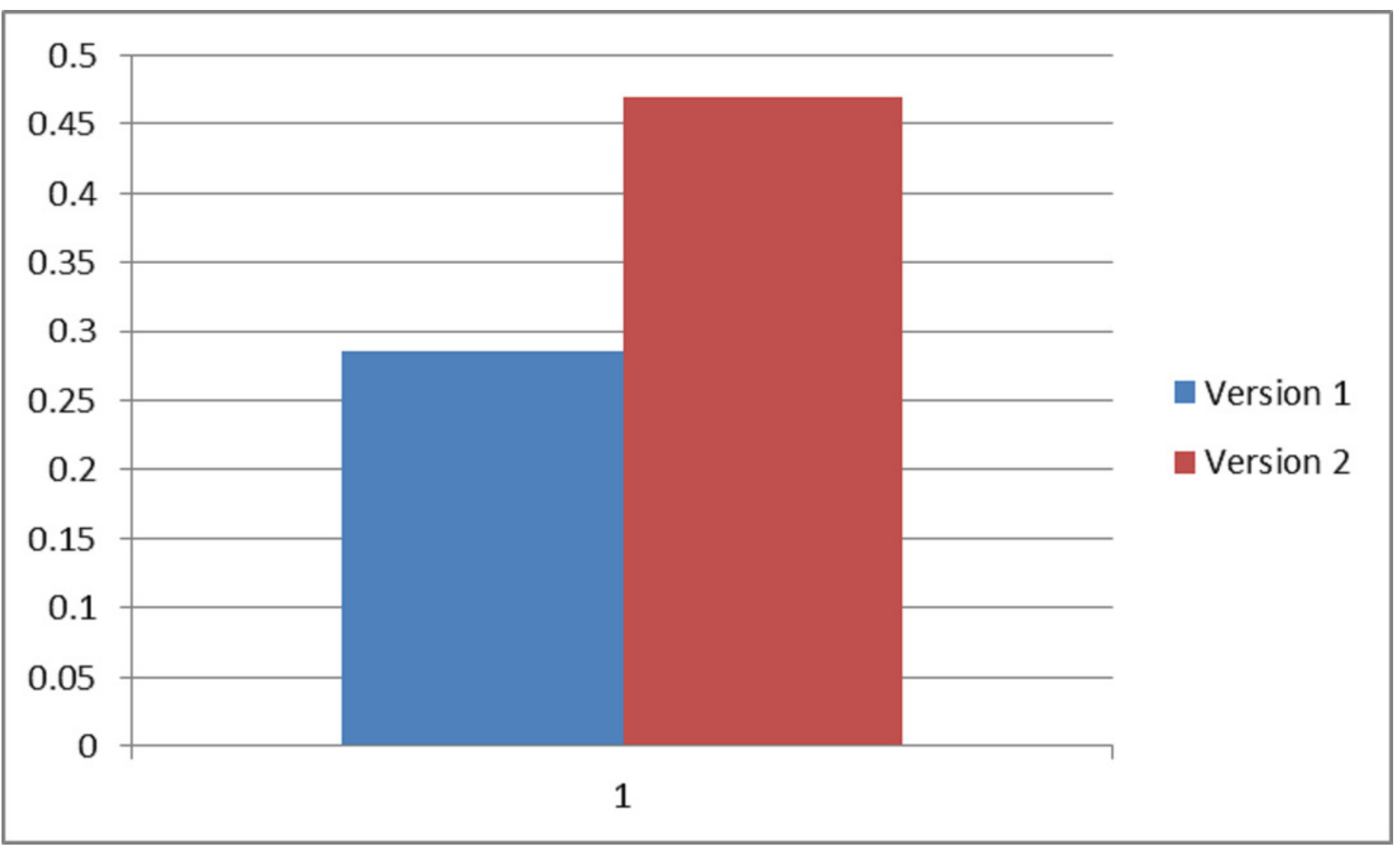


Figure 7

Graphical representation of Security Durability Impact at Level 1

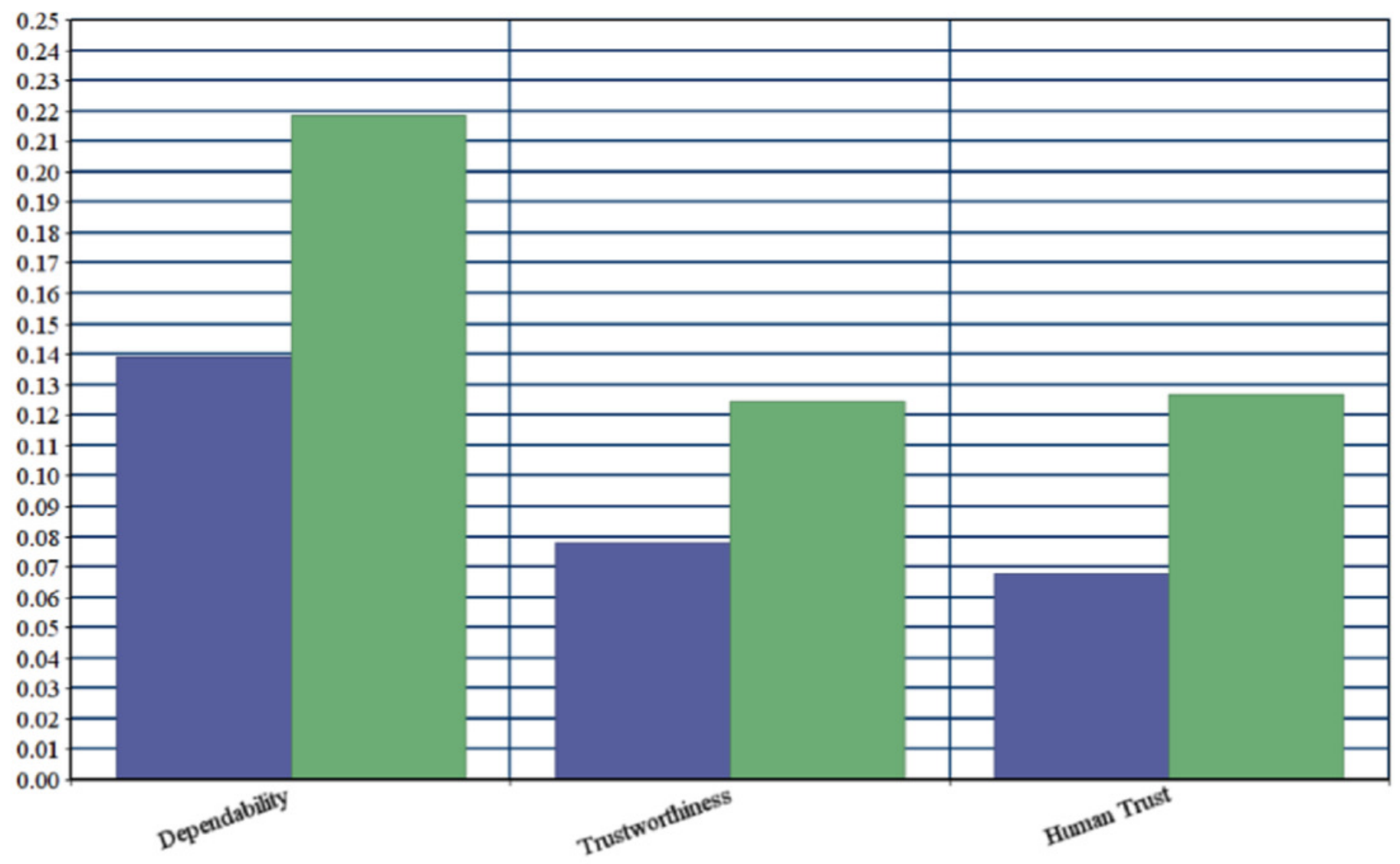


Figure 8

Graphical representation of Security Durability Impact at Level 2

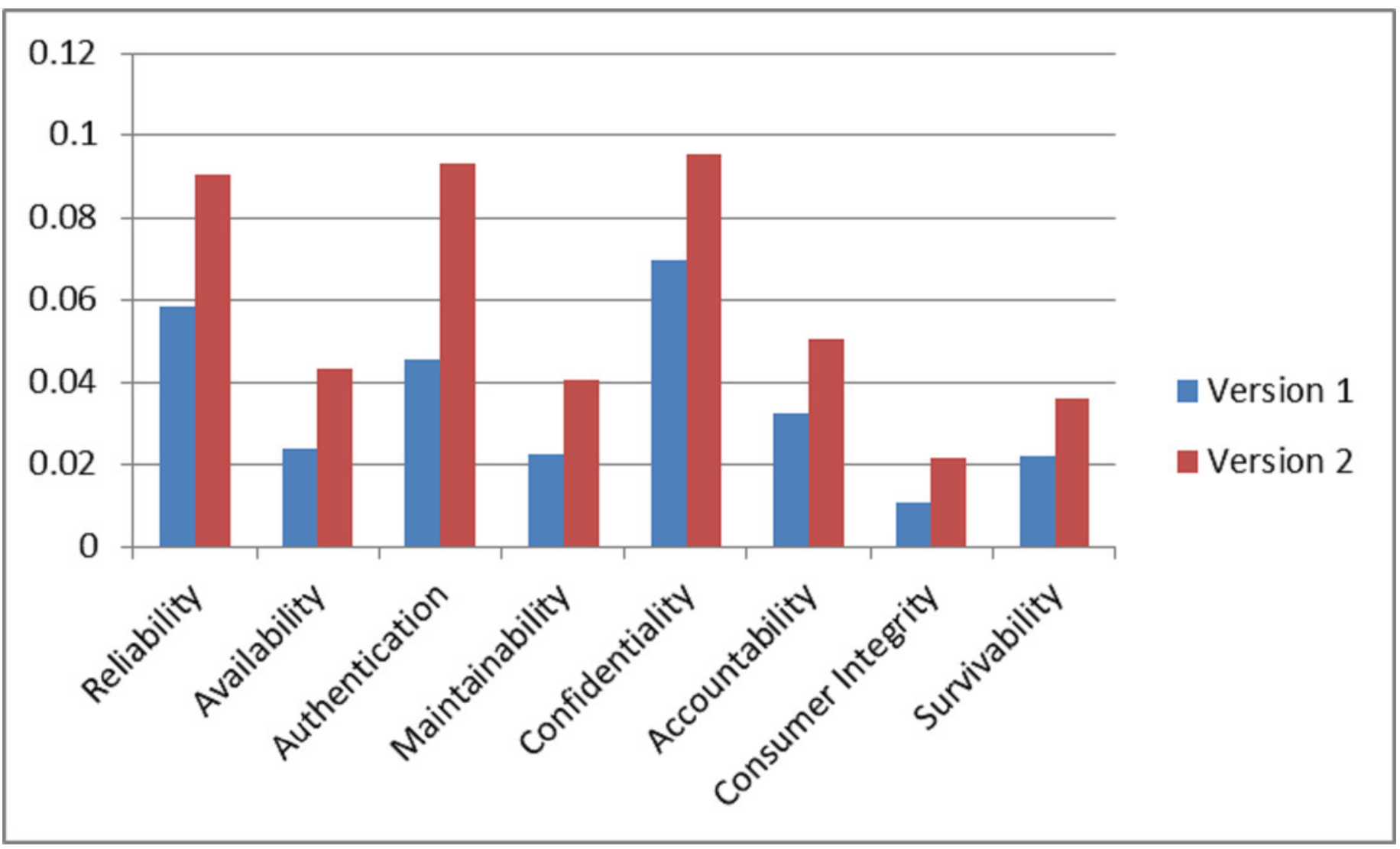


Figure 9

Graphical representation of Security Durability Impact at Level 3

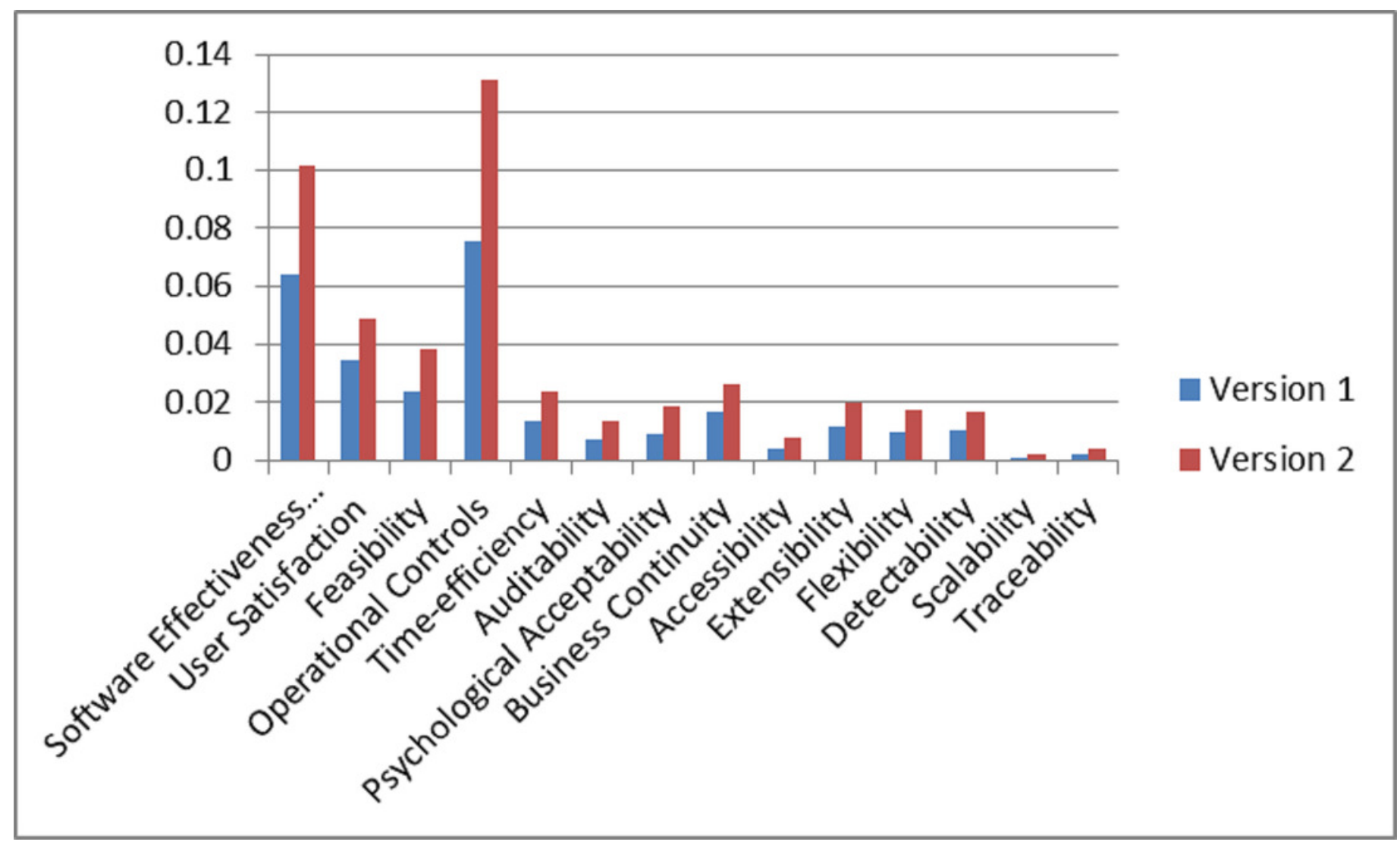


Figure 10

\section{Graphical Representation of Sensitivity Analysis}

Sensitrity Analysis

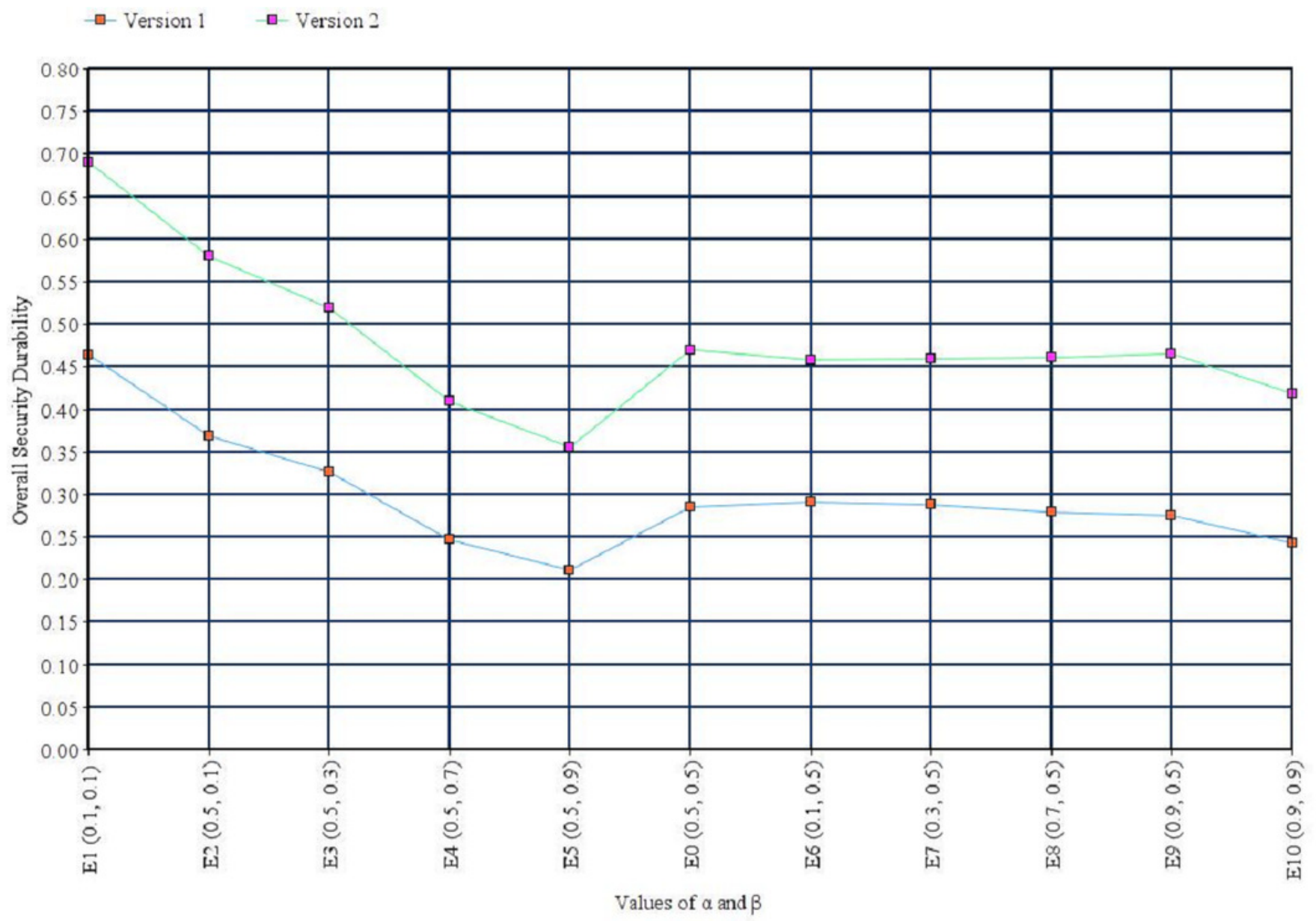




\section{Table $\mathbf{1}$ (on next page)}

Corresponding Linguistic Scale for Membership Functions 
Table 1: Corresponding Linguistic Scale for Membership Functions

2

\begin{tabular}{|c|c|c|c|c|}
\hline $\begin{array}{l}\text { S. } \\
\text { No. }\end{array}$ & Linguistic Values & $\begin{array}{c}\text { Numeric } \\
\text { Values }\end{array}$ & $\begin{array}{c}\text { Fuzzified Numbers } \\
\text { (TFNs) [aij] }\end{array}$ & $1 /[a \mathbf{i j}]$ \\
\hline 1 & Equal Important (Eq) & 1 & $(1,1,1)$ & $(1,1,1)$ \\
\hline 2 & $\begin{array}{c}\text { Intermediate Value between Equal and } \\
\text { Weakly (E \& W) }\end{array}$ & 2 & $(1,2,3)$ & $(1 / 3,1 / 2,1)$ \\
\hline 3 & Weakly Important (WI) & 3 & $(2,3,4)$ & $(1 / 4,1 / 3,1 / 2)$ \\
\hline 4 & $\begin{array}{c}\text { Intermediate Value between Weakly and } \\
\text { Essential (W \& E) }\end{array}$ & 4 & $(3,4,5)$ & $(1 / 5,1 / 4,1 / 3)$ \\
\hline 5 & Essential Important (EI) & 5 & $(4,5,6)$ & $(1 / 6,1 / 5,1 / 4)$ \\
\hline 6 & $\begin{array}{c}\text { Intermediate Value between Essential and } \\
\text { Very Strongly (E \& VS) }\end{array}$ & 6 & $(5,6,7)$ & $(1 / 7,1 / 6,1 / 5)$ \\
\hline 7 & Very Strongly Important (VS) & 7 & $(6,7,8)$ & $(1 / 8,1 / 7,1 / 6)$ \\
\hline 8 & $\begin{array}{c}\text { Intermediate Value between Very Strongly } \\
\text { and Extremely (VS \& ES) }\end{array}$ & 8 & $(7,8,9)$ & $(1 / 9,1 / 8,1 / 7)$ \\
\hline 9 & Extremely Important (ES) & 9 & $(7,9,9)$ & $(1 / 9,1 / 9,1 / 7)$ \\
\hline
\end{tabular}




\section{Table 2 (on next page)}

Linguistic Rating Scale 
2

Table 2: Linguistic Rating Scale

\begin{tabular}{cccc}
\hline $\begin{array}{c}\text { S. } \\
\text { No. }\end{array}$ & $\begin{array}{c}\text { Linguistic } \\
\text { Value }\end{array}$ & $\begin{array}{c}\text { Numeric Value } \\
\text { of Ratings }\end{array}$ & $\begin{array}{c}\text { Fuzzified Ratings } \\
(\text { TFNs) }\end{array}$ \\
\hline 1 & Very Low (VL) & 0.1 & $(0.0,0.1,0.3)$ \\
2 & Low (L) & 0.3 & $(0.1,0.3,0.5)$ \\
3 & Medium (M) & 0.5 & $(0.3,0.5,0.7)$ \\
4 & High (H) & 0.7 & $(0.5,0.7,0.9)$ \\
5 & $\begin{array}{c}\text { Very High } \\
\text { (VH) }\end{array}$ & 0.9 & $(0.7,0.9,1.0)$
\end{tabular}

3 


\section{Table 3 (on next page)}

Random Index 
1

2

\begin{tabular}{llllllllll}
\multicolumn{10}{c}{ Table 3: Random Index } \\
\hline $\mathbf{N}$ & $\mathbf{1}$ & $\mathbf{2}$ & $\mathbf{3}$ & $\mathbf{4}$ & $\mathbf{5}$ & $\mathbf{6}$ & $\mathbf{7}$ & $\mathbf{8}$ & $\mathbf{9}$ \\
\hline $\begin{array}{l}\text { Random } \\
\text { Index }\end{array}$ & 0.00 & 0.00 & 0.58 & 0.90 & 1.12 & 1.24 & 1.35 & 1.41 & 1.49
\end{tabular}

Table 3: Random Index

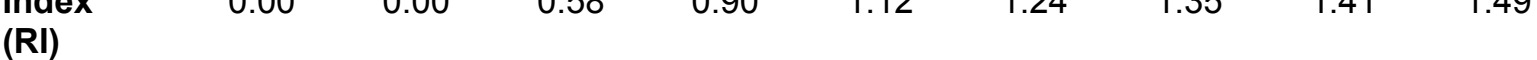




\section{Table 4 (on next page)}

Aggregated Fuzzify Pair Wise Comparison Matrix for the First Level 
Table 4: Aggregated Fuzzify Pair Wise Comparison Matrix for the First Level

\begin{tabular}{clll}
\hline & \multicolumn{1}{c}{$\begin{array}{c}\text { Dependability } \\
(\mathrm{C} 1)\end{array}$} & \multicolumn{1}{c}{$\begin{array}{c}\text { Trustworthiness } \\
(\mathrm{C} 2)\end{array}$} & $\begin{array}{l}\text { Human Trust } \\
(\mathrm{C} 3)\end{array}$ \\
\hline $\begin{array}{c}\text { Dependability } \\
\text { (C1) }\end{array}$ & 1 & $1.3479,1.8180$, & $1.4131,1.9651$, \\
Trustworthines & - & 2.3859 & 2.4820 \\
$\quad$ s (C2) & & 1 & $0.8540,1.1087$, \\
Human Trust & - & & 1.4532 \\
(C3) & & - & 1
\end{tabular}

2 


\section{Table 5 (on next page)}

Aggregated Fuzzify Pair Wise Comparison Matrix for C1 of Second Level 


\begin{tabular}{|c|c|c|c|c|c|}
\hline & 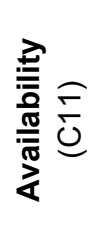 & 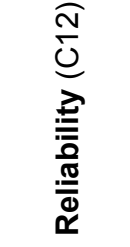 & 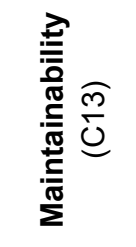 & 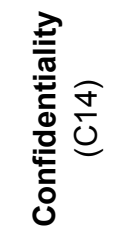 & 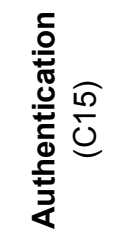 \\
\hline $\begin{array}{c}\text { Availability } \\
\text { (C11) }\end{array}$ & 1 & $\begin{array}{c}0.3127 \\
0.4395 \\
0.6252\end{array}$ & $\begin{array}{l}0.8733 \\
0.9012 \\
0.9465\end{array}$ & $\begin{array}{c}0.2261 \\
0.2928 \\
0.4166\end{array}$ & $\begin{array}{l}0.2580 \\
0.3386 \\
0.5055\end{array}$ \\
\hline $\begin{array}{c}\text { Reliability } \\
\text { (C12) }\end{array}$ & - & 1 & $\begin{array}{c}2.0451 \\
3.1699 \\
4.2330\end{array}$ & $\begin{array}{c}0.2665 \\
0.3657 \\
0.5911\end{array}$ & $\begin{array}{c}0.6906 \\
1.0059 \\
1.5117\end{array}$ \\
\hline $\begin{array}{c}\text { Maintainability } \\
\text { (C13) }\end{array}$ & - & - & 1 & $\begin{array}{c}0.3667 \\
0.5251 \\
0.9659\end{array}$ & $\begin{array}{c}0.3604 \\
0.5220 \\
0.8074\end{array}$ \\
\hline $\begin{array}{c}\text { Confidentiality } \\
\text { (C14) }\end{array}$ & - & - & - & 1 & $\begin{array}{l}0.8960 \\
1.1486 \\
1.3903\end{array}$ \\
\hline $\begin{array}{l}\text { Authentication } \\
\text { (C15) }\end{array}$ & - & - & - & - & 1 \\
\hline
\end{tabular}




\section{Table 6(on next page)}

Aggregated Fuzzify Pair Wise Comparison Matrix for C2 of Second Level 


\begin{tabular}{|c|c|c|c|c|c|}
\hline & 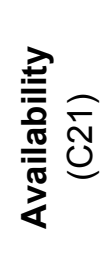 & 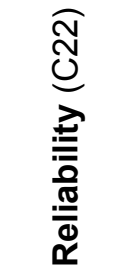 & 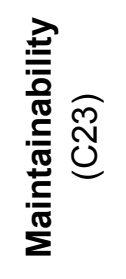 & 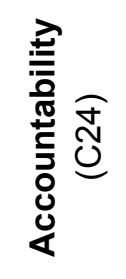 & 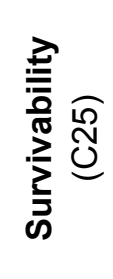 \\
\hline $\begin{array}{l}\text { Availability } \\
\text { (C21) }\end{array}$ & 1 & $\begin{array}{l}0.5598 \\
0.8994 \\
1.3705\end{array}$ & $\begin{array}{l}0.7912 \\
0.8831 \\
1.0204\end{array}$ & $\begin{array}{l}0.4956 \\
0.7029 \\
0.9330\end{array}$ & $\begin{array}{l}0.4067 \\
0.5497 \\
0.7876\end{array}$ \\
\hline $\begin{array}{l}\text { Reliability } \\
\text { (C22) }\end{array}$ & - & 1 & $\begin{array}{l}0.8001 \\
1.2376 \\
1.7812\end{array}$ & $\begin{array}{l}0.3836 \\
0.5483 \\
0.8344\end{array}$ & $\begin{array}{l}0.4876 \\
0.6710 \\
0.8900\end{array}$ \\
\hline $\begin{array}{l}\text { Maintainability } \\
\text { (C23) }\end{array}$ & - & - & 1 & $\begin{array}{l}0.5966 \\
0.7093 \\
0.9095\end{array}$ & $\begin{array}{l}0.2770 \\
0.3854 \\
0.6340\end{array}$ \\
\hline $\begin{array}{l}\text { Accountability } \\
\text { (C24) }\end{array}$ & - & - & - & 1 & $\begin{array}{l}0.5506 \\
0.5881 \\
0.6647\end{array}$ \\
\hline $\begin{array}{l}\text { Survivability } \\
\text { (C25) }\end{array}$ & - & - & - & - & 1 \\
\hline
\end{tabular}




\section{Table 7 (on next page)}

Aggregated Fuzzify Pair Wise Comparison Matrix for C3 of Second Level 


\begin{tabular}{|c|c|c|c|c|c|}
\hline & 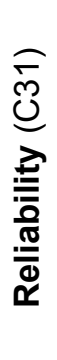 & 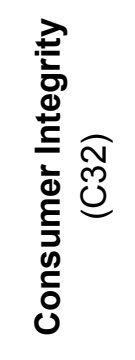 & 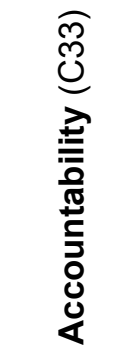 & 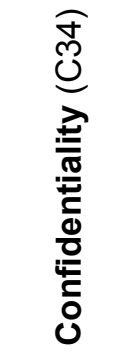 & 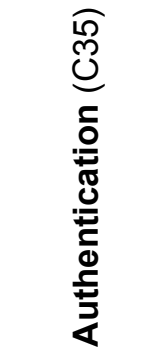 \\
\hline $\begin{array}{c}\text { Reliability } \\
\text { (C31) }\end{array}$ & 1 & $\begin{array}{l}0.9710 \\
1.2475 \\
1.6094\end{array}$ & $\begin{array}{l}1.0592 \\
1.5849 \\
2.2206\end{array}$ & $\begin{array}{c}0.7733 \\
1.0118 \\
1.2881\end{array}$ & $\begin{array}{c}0.7612 \\
0.9120 \\
1.0965\end{array}$ \\
\hline $\begin{array}{l}\text { Consumer Integrity } \\
\text { (C32) }\end{array}$ & - & 1 & $\begin{array}{c}0.6352 \\
0.9143 \\
1.3430\end{array}$ & $\begin{array}{c}0.4273 \\
0.6335 \\
0.9660\end{array}$ & $\begin{array}{c}0.3476 \\
0.4900 \\
0.8734\end{array}$ \\
\hline Accountability (C33) & - & - & 1 & $\begin{array}{c}0.5146 \\
0.6575 \\
0.7846\end{array}$ & $\begin{array}{c}0.5213 \\
0.6597 \\
0.9191\end{array}$ \\
\hline Confidentiality (C34) & - & - & - & 1 & $\begin{array}{c}0.5562,0 \\
6448,0.8 \\
122\end{array}$ \\
\hline Authentication (C35) & - & - & - & - & 1 \\
\hline
\end{tabular}




\section{Table 8(on next page)}

Aggregated Fuzzify Pair Wise Comparison Matrix for C11 of Third Level 


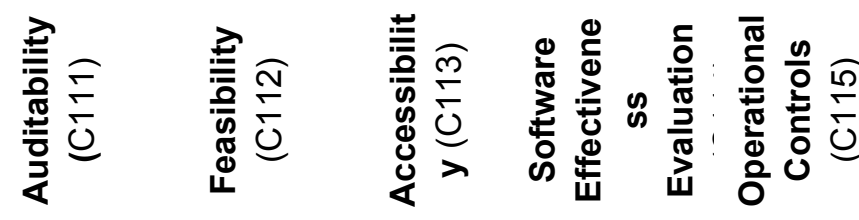

\begin{tabular}{|c|c|c|c|c|c|}
\hline $\begin{array}{l}\text { Auditability } \\
\text { (C111) }\end{array}$ & 1 & $\begin{array}{l}1.8722 \\
2.5710 \\
3.2035\end{array}$ & $\begin{array}{l}1.4640 \\
1.6842 \\
1.9743\end{array}$ & $\begin{array}{l}1.4461 \\
2.4385 \\
3.3865\end{array}$ & $\begin{array}{l}0.4677 \\
0.5724, \\
0.7845\end{array}$ \\
\hline $\begin{array}{l}\text { Feasibility } \\
\text { (C112) }\end{array}$ & - & 1 & $\begin{array}{c}0.6083, \\
0.7754 \\
1.0265\end{array}$ & $\begin{array}{l}0.7708 \\
0.9504 \\
1.2361\end{array}$ & $\begin{array}{l}0.1630 \\
0.1953, \\
0.2497\end{array}$ \\
\hline $\begin{array}{l}\text { Accessibility } \\
\text { (C113) }\end{array}$ & - & - & 1 & $\begin{array}{c}0.7694,1 \\
.0502 \\
1.3553\end{array}$ & $\begin{array}{l}0.2086, \\
0.2462 \\
0.3117\end{array}$ \\
\hline $\begin{array}{l}\text { Software } \\
\text { Effectiveness } \\
\text { Evaluation } \\
\text { (C114) }\end{array}$ & - & - & - & 1 & $\begin{array}{l}0.1956, \\
0.2283, \\
0.2903\end{array}$ \\
\hline $\begin{array}{l}\text { Operational } \\
\text { Controls } \\
(\mathrm{C} 115)\end{array}$ & - & - & - & - & 1 \\
\hline
\end{tabular}

2 


\section{Table 9 (on next page)}

Aggregated Fuzzify Pair Wise Comparison Matrix for the C12 of Third Level 


\begin{tabular}{|c|c|c|c|c|}
\hline & 胥 & 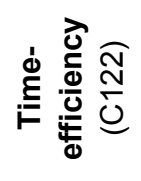 & 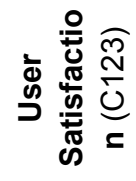 & 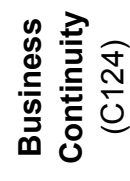 \\
\hline $\begin{array}{l}\text { Feasibility } \\
\text { (C121) }\end{array}$ & 1 & $\begin{array}{l}1.7561 \\
2.3498 \\
3.0335\end{array}$ & $\begin{array}{l}1.4830 \\
1.9575 \\
2.5293\end{array}$ & $\begin{array}{l}1.1284, \\
1.5543, \\
1.9884\end{array}$ \\
\hline $\begin{array}{l}\text { Time-efficiency } \\
\text { (C122) }\end{array}$ & - & 1 & $\begin{array}{c}0.5695 \\
0.7860 \\
1.1555\end{array}$ & $\begin{array}{c}0.5698 \\
0.7195 \\
0.9699\end{array}$ \\
\hline $\begin{array}{l}\text { User } \\
\text { Satisfaction } \\
\text { (C123) }\end{array}$ & - & - & 1 & $\begin{array}{c}0.6270 \\
0.8123 \\
1.0718\end{array}$ \\
\hline $\begin{array}{l}\text { Business } \\
\text { Continuity } \\
(\mathrm{C} 124)\end{array}$ & - & - & - & 1 \\
\hline
\end{tabular}




\section{Table $\mathbf{1 0}$ (on next page)}

Aggregated Fuzzify Pair Wise Comparison Matrix for the C13 of Third Level 


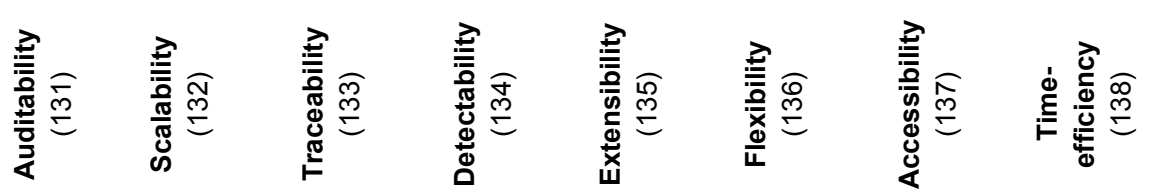

\begin{tabular}{|c|c|c|c|c|c|c|c|c|}
\hline $\begin{array}{c}\text { Auditability } \\
(131)\end{array}$ & 1 & $\begin{array}{l}1.0000 \\
\text { ' } \\
\text { ' } 1.5157 \\
1.9331\end{array}$ & $\begin{array}{l}0.4896 \\
0.6372 \\
1.0000\end{array}$ & $\begin{array}{l}0.4152 \\
, \\
0.5743 \\
1.0000\end{array}$ & $\begin{array}{l}0.2215 \\
0.2871 \\
0.4152\end{array}$ & $\begin{array}{l}0.3146 \\
0.4610 \\
0.8705\end{array}$ & $\begin{array}{l}0.6575 \\
1.1653 \\
1.6883\end{array}$ & $\begin{array}{l}0.2444 \\
0.3238 \\
0.4801\end{array}$ \\
\hline $\begin{array}{c}\text { Scalability } \\
(132)\end{array}$ & - & 1 & $\begin{array}{l}0.5743 \\
, \\
0.6657 \\
0.8022\end{array}$ & $\begin{array}{l}0.3039 \\
, 0.3936 \\
0.5661\end{array}$ & $\begin{array}{l}0.2679 \\
0.3521 \\
0.5176\end{array}$ & $\begin{array}{l}0.1663 \\
\dot{0} \\
0.1969 \\
0.2531\end{array}$ & $\begin{array}{l}0.3930 \\
, \\
0.5743 \\
1.0564\end{array}$ & $\begin{array}{l}0.1692 \\
0.2076 \\
0.2759\end{array}$ \\
\hline $\begin{array}{c}\text { Traceability } \\
\text { (133) }\end{array}$ & - & - & 1 & $\begin{array}{l}1.0000 \\
, \\
1.3195 \\
\text { ' }\end{array}$ & $\begin{array}{l}0.3009 \\
0.4352 \\
0.8027\end{array}$ & $\begin{array}{l}0.8027 \\
0.8705 \\
1.0000\end{array}$ & $\begin{array}{l}1.2619 \\
1.8250 \\
2.4334\end{array}$ & $\begin{array}{l}0.1728 \\
0.2091 \\
0.2648\end{array}$ \\
\hline $\begin{array}{l}\text { Detectabilit } \\
\text { y (134) }\end{array}$ & - & - & - & 1 & $\begin{array}{l}0.5386 \\
0.9143 \\
1.5836\end{array}$ & $\begin{array}{l}0.6083 \\
1.0592 \\
1.6829\end{array}$ & $\begin{array}{l}0.7503 \\
1.3465 \\
1.9611\end{array}$ & $\begin{array}{l}0.6790 \\
0.7489, \\
0.8705\end{array}$ \\
\hline $\begin{array}{l}\text { Extensibilit } \\
\text { y (135) }\end{array}$ & - & - & - & - & 1 & $\begin{array}{l}0.4152 \\
0.6372 \\
1.1791\end{array}$ & $\begin{array}{l}0.9465 \\
1.1095 \\
1.2457\end{array}$ & $\begin{array}{l}0.2500 \\
0.3300 \\
0.5000\end{array}$ \\
\hline $\begin{array}{l}\text { Flexibility } \\
\text { (136) }\end{array}$ & - & - & - & - & - & 1 & $\begin{array}{l}1.8881 \\
2.5508 \\
3.1697\end{array}$ & $\begin{array}{l}0.8027, \\
1.0352, \\
1.3160\end{array}$ \\
\hline $\begin{array}{c}\text { Accessibilit } \\
\text { y (137) }\end{array}$ & - & - & - & - & - & - & 1 & $\begin{array}{l}0.2136, \\
0.2575, \\
0.3195\end{array}$ \\
\hline $\begin{array}{c}\text { Time- } \\
\text { efficiency } \\
(138)\end{array}$ & - & - & - & - & - & - & - & 1 \\
\hline
\end{tabular}




\section{Table $\mathbf{1 1}$ (on next page)}

Aggregated Fuzzify Pair Wise Comparison Matrix for the C14 of Third Level 


\begin{tabular}{|c|c|c|c|}
\hline & 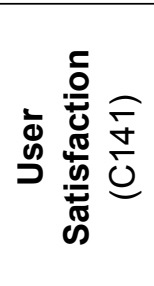 & 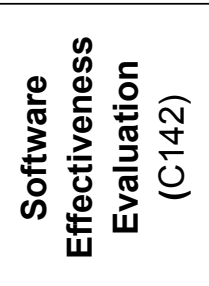 & 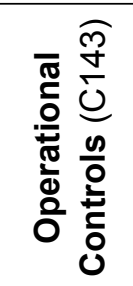 \\
\hline $\begin{array}{l}\text { User Satisfaction } \\
\qquad(\mathrm{C} 141)\end{array}$ & 1 & $\begin{array}{c}0.6898 \\
0.8860 \\
1.1002\end{array}$ & $\begin{array}{l}0.2255, \\
0.2762, \\
0.3574\end{array}$ \\
\hline $\begin{array}{c}\text { Software } \\
\text { Effectiveness } \\
\text { Evaluation (C142) }\end{array}$ & - & 1 & $\begin{array}{l}0.3051 \\
0.3892 \\
0.5609\end{array}$ \\
\hline $\begin{array}{c}\text { Operational } \\
\text { Controls (C143) }\end{array}$ & - & - & 1 \\
\hline
\end{tabular}




\section{Table 12 (on next page)}

Aggregated Fuzzify Pair Wise Comparison Matrix for the C15 of Third Level 

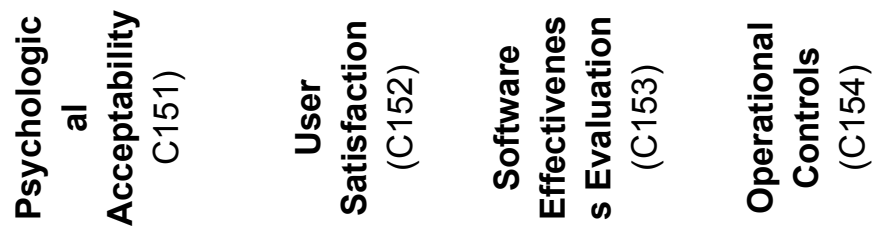

Psychological

Acceptability

(C151)

User

Satisfaction

(C152)

Software

Effectiveness

Evaluation

(C153)

Operational

Controls (C154)

$\begin{array}{lll}1.0000, & 0.5610, & 0.3040 \\ 1.3741, & 0.8360, & 0.3766 \\ 1.7118 & 1.0781 & 0.4723 \\ 1 & & \\ & 0.3030, & 0.1916 \\ & 0.4208, & 0.2303 \\ - & 0.6052 & 0.3001 \\ & 1 & 0.5138 \\ & & 0.7959 \\ & & 1.2032\end{array}$

1.0000,

1

(1)

$-2$

-

$-$

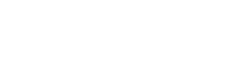

2 


\section{Table $\mathbf{1 3}$ (on next page)}

Aggregated Fuzzify Pair Wise Comparison Matrix for the C25 of Third Level 
Table 13: Aggregated Fuzzify Pair Wise Comparison Matrix for the C25 of Third Level

\begin{tabular}{|c|c|c|c|}
\hline & $\begin{array}{l}\text { Detectability } \\
\text { (C251) }\end{array}$ & $\begin{array}{l}\text { Extensibility } \\
\text { (C252) }\end{array}$ & $\begin{array}{l}\text { Flexibility } \\
\text { (C253) }\end{array}$ \\
\hline $\begin{array}{l}\text { Detectability } \\
\text { (C251) }\end{array}$ & 1 & $\begin{array}{l}0.6950 \\
0.9502 \\
1.3457\end{array}$ & $\begin{array}{l}1.1486 \\
1.4385 \\
1.6962\end{array}$ \\
\hline $\begin{array}{l}\text { Extensibility } \\
\text { (C252) }\end{array}$ & - & 1 & $\begin{array}{l}1.1928 \\
1.5826 \\
2.1497\end{array}$ \\
\hline $\begin{array}{l}\text { Flexibility } \\
\text { (C253) }\end{array}$ & - & - & 1 \\
\hline
\end{tabular}

2 


\section{Table 14(on next page)}

Aggregated Fuzzify Pair Wise Comparison Matrix for the C32 of Third Level 

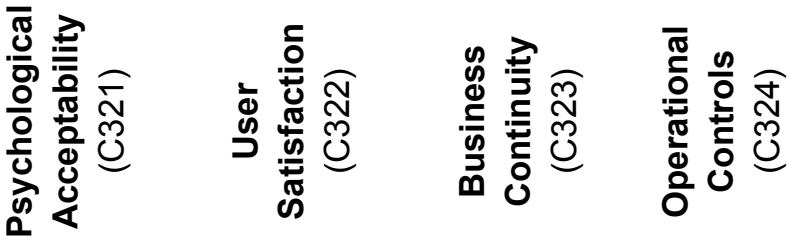

\section{Psychological \\ Acceptability}

(C321)

User

Satisfaction

(C322)

Business

Continuity

(C323)

Operational

Controls (C324)
1

1.5990

2.1130

1

$\begin{array}{ll}0.3230, & 0.2584\end{array}$

$0.4480, \quad 0.3172$

$0.6051 \quad 0.4168$

$1 \quad 0.6661$,

1.0564,

1.5427

3 


\section{Table 15(on next page)}

Local Weight of Attributes for First Level through Fuzzy Method 


\begin{tabular}{|c|c|c|c|c|}
\hline & $\begin{array}{l}\frac{7}{0} \\
\frac{0}{0} \\
\frac{\pi}{0} \\
\frac{0}{0} \\
\frac{0}{0} \\
\frac{0}{0}\end{array}$ & 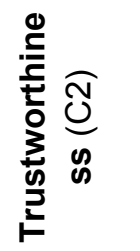 & 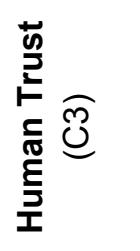 & Weights \\
\hline $\begin{array}{l}\text { Dependability } \\
\text { (C1) }\end{array}$ & 1 & 1.8425 & 1.9564 & 0.4867 \\
\hline Trustworthines & 0.5 & & & \\
\hline $\mathbf{s}(\mathrm{C} 2)$ & $\begin{array}{c}42 \\
7\end{array}$ & 1 & 1.1312 & 0.2698 \\
\hline $\begin{array}{l}\text { Human Trust } \\
\text { (C3) }\end{array}$ & $\begin{array}{c}0.5 \\
11 \\
1\end{array}$ & 0.8840 & 1 & 0.2435 \\
\hline
\end{tabular}

2 


\section{Table $\mathbf{1 6}$ (on next page)}

Local Weight of Attributes for $\mathrm{C} 1$ of Second Level through Fuzzy Method 


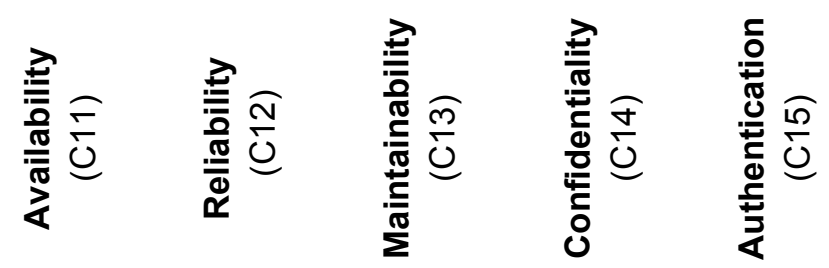

Weights

\begin{tabular}{|c|c|c|c|c|c|c|}
\hline & 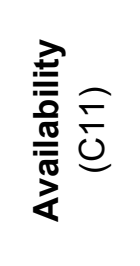 & 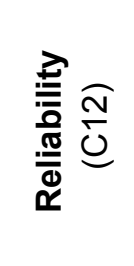 & 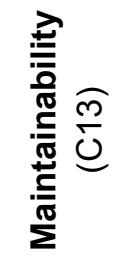 & 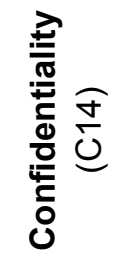 & 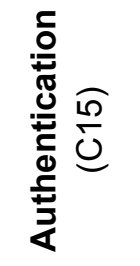 & Weights \\
\hline $\begin{array}{c}\text { Availability } \\
\text { (C11) }\end{array}$ & 1 & 0.4542 & 0.9056 & 0.3071 & 0.3602 & 0.0946 \\
\hline $\begin{array}{l}\text { Reliability } \\
\quad(\mathrm{C} 12)\end{array}$ & 2.2017 & 1 & 3.1545 & 0.3973 & 1.0536 & 0.2292 \\
\hline $\begin{array}{l}\text { Maintainability } \\
\text { (C13) }\end{array}$ & 1.1042 & $\begin{array}{c}0.3170 \\
1\end{array}$ & 1 & 0.5957 & 0.5530 & 0.1192 \\
\hline $\begin{array}{l}\text { Confidentiality } \\
\text { (C14) }\end{array}$ & 3.2563 & 2.5170 & 1.6787 & 1 & 1.1459 & 0.3233 \\
\hline $\begin{array}{l}\text { Authentication } \\
\text { (C15) }\end{array}$ & 2.7762 & 0.9491 & 1.8083 & 0.8727 & 1 & 0.2337 \\
\hline & & & & & \multicolumn{2}{|c|}{ C.R. $=0.0411$} \\
\hline
\end{tabular}

2 


\section{Table 17 (on next page)}

Local Weight of Attributes for C2 of Second Level through Fuzzy Method 


\begin{tabular}{|c|c|c|c|c|c|c|}
\hline & 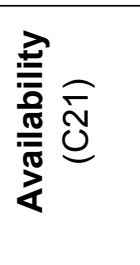 & 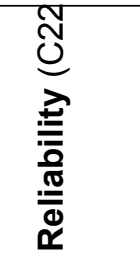 & 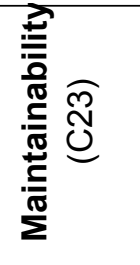 & 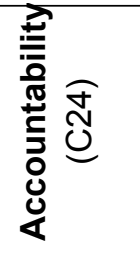 & 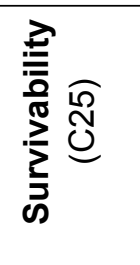 & Weights \\
\hline $\begin{array}{c}\text { Availability } \\
\text { (C21) }\end{array}$ & 1 & 0.9323 & 0.8945 & 0.7086 & 0.5734 & 0.1541 \\
\hline $\begin{array}{l}\text { Reliability } \\
\quad(\mathrm{C} 22)\end{array}$ & 1.0726 & 1 & 1.2642 & 0.5787 & 0.6647 & 0.1692 \\
\hline $\begin{array}{l}\text { Maintainabilit } \\
\quad y(C 23)\end{array}$ & 1.1179 & 0.7910 & 1 & 0.7304 & 0.4205 & 0.1476 \\
\hline $\begin{array}{l}\text { Accountabilit } \\
\quad y(C 24)\end{array}$ & 1.4112 & 1.7280 & 1.3691 & 1 & 0.5979 & 0.2214 \\
\hline $\begin{array}{l}\text { Survivability } \\
\text { (C25) }\end{array}$ & 1.7440 & 1.5044 & 2.3781 & 1.6725 & 1 & 0.3077 \\
\hline
\end{tabular}




\section{Table 18 (on next page)}

Local Weight of Attributes for C3 of Second Level through Fuzzy Method 
Table 18: Local Weight of Attributes for C3 of Second Level through Fuzzy Method

\begin{tabular}{|c|c|c|c|c|c|c|}
\hline & 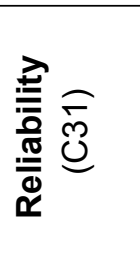 & 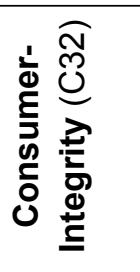 & 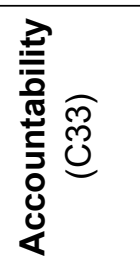 & 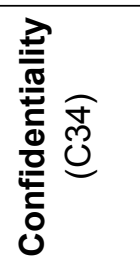 & 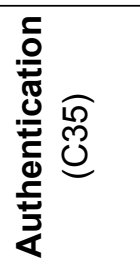 & Weights \\
\hline $\begin{array}{l}\text { Reliability } \\
\text { (C31) }\end{array}$ & 1 & 1.2689 & 1.6124 & 1.0213 & 0.9204 & 0.2216 \\
\hline $\begin{array}{l}\text { Consumer } \\
\text { Integrity (C32) }\end{array}$ & 0.7881 & 1 & 1.2693 & 0.6651 & 0.5503 & 0.1596 \\
\hline $\begin{array}{l}\text { Accountabilit } \\
\text { y (C33) }\end{array}$ & 0.6202 & 0.7878 & 1 & 0.6536 & 0.6900 & 0.1446 \\
\hline $\begin{array}{l}\text { Confidentialit } \\
\text { y (C34) }\end{array}$ & 0.9791 & 1.5035 & 1.5300 & 1 & 0.6645 & 0.2115 \\
\hline $\begin{array}{l}\text { Authenticatio } \\
\mathbf{n}(\mathrm{C} 35)\end{array}$ & 1.0865 & 1.8172 & 1.4493 & 1.5049 & 1 & 0.2627 \\
\hline & & & & & \multicolumn{2}{|c|}{ C.R. $=0.0069$} \\
\hline
\end{tabular}

2 


\section{Table 19(on next page)}

Local Weight of Attributes for C11 of Third Level through Fuzzy Method 


\begin{tabular}{|c|c|c|c|c|c|c|}
\hline & 总 & 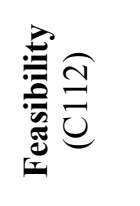 & 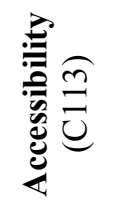 & 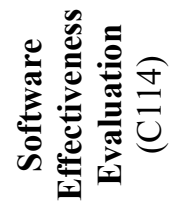 & 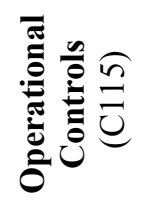 & Weights \\
\hline $\begin{array}{l}\text { Auditability } \\
\text { (C111) }\end{array}$ & 1 & 2.5544 & 1.7017 & 2.4274 & 0.5993 & 0.2400 \\
\hline $\begin{array}{l}\text { Feasibility } \\
\text { (C112) }\end{array}$ & 0.3915 & 1 & 0.7964 & 0.9769 & 0.2073 & 0.0952 \\
\hline $\begin{array}{l}\text { Accessibility } \\
\text { (C113) }\end{array}$ & 0.5876 & 1.2556 & 1 & 1.0563 & 0.2532 & 0.1200 \\
\hline $\begin{array}{l}\text { Software } \\
\text { Effectiveness } \\
\text { Evaluation } \\
(\mathrm{C} 114)\end{array}$ & 0.4120 & 1.0236 & 0.9467 & 1 & 0.2357 & 0.1032 \\
\hline $\begin{array}{l}\text { Operational } \\
\text { Controls } \\
(\mathrm{C} 115)\end{array}$ & 1.6686 & 4.8239 & 3.9495 & 4.2427 & 1 & 0.4416 \\
\hline
\end{tabular}




\section{Table 20 (on next page)}

Local Weight of Attributes for C12 of Third Level through Fuzzy Method 


Feasibility
(C121)

(C121)

Time-efficiency

(C122)

User

Satisfaction

(C123)

Business

Continuity

(C124)

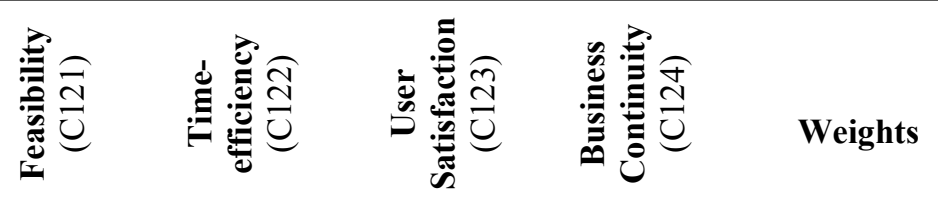

$\begin{array}{lll}0.6425 & 1.3428 & 1.2035\end{array}$

0.5046
0.6425

1.2132

2.3723

1.9819

1.5564

0.8243

0.7447

0.3905

0.4215

1

0.8243

$1 \quad 0.8309$

0.2004 


\section{Table 21 (on next page)}

Local Weight of Attributes for C13 of Third Level through Fuzzy Method 
Table 21: Local Weight of Attributes for C13 of Third Level through Fuzzy Method

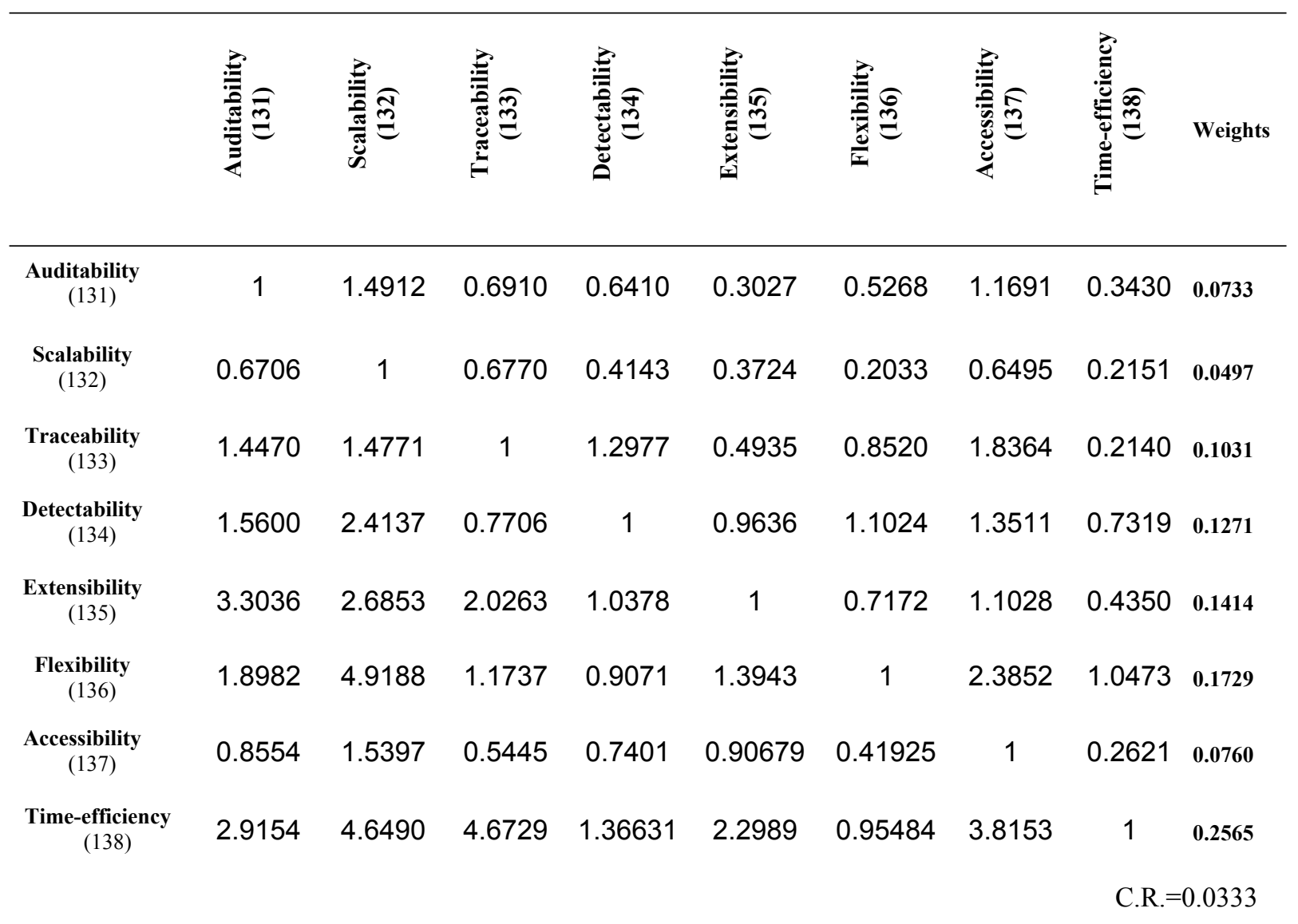




\section{Table 22 (on next page)}

Local Weight of Attributes for C14 of Third Level through Fuzzy Method 
2

\begin{tabular}{|c|c|c|c|c|}
\hline & 离言离 & 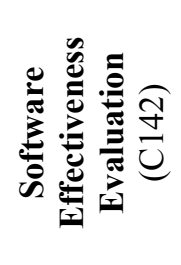 & 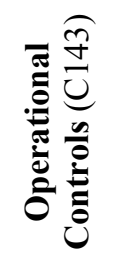 & Weights \\
\hline $\begin{array}{l}\text { User Satisfaction } \\
\quad(\mathrm{C} 141)\end{array}$ & 1 & 0.8905 & 0.2839 & 0.1832 \\
\hline $\begin{array}{c}\text { Software Effectiveness } \\
\text { Evaluation } \\
\text { (C142) }\end{array}$ & 1.1230 & 1 & 0.4111 & 0.2239 \\
\hline $\begin{array}{c}\text { Operational Controls } \\
\text { (C143) }\end{array}$ & 3.5224 & 2.4325 & 1 & 0.5929 \\
\hline & & & & $\mathrm{R}=0.0062$ \\
\hline
\end{tabular}

3 


\section{Table 23 (on next page)}

Local Weight of Attributes for C15 of Third Level through Fuzzy Method 

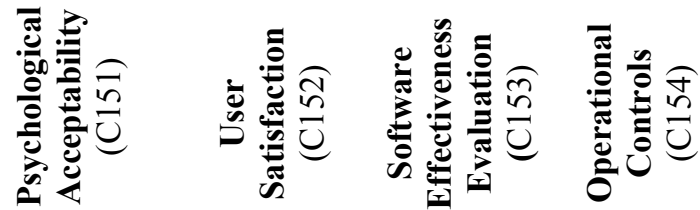

Weights

Psychological
Acceptability (C151)

1
User Satisfaction (C152)

0.7325

1.3651

0.8278

0.3824

0.1811

Software

Effectiveness

Evaluation (C153)

1.2080

2.2857

0.4375

0.2381

0.1167

Operational Controls

(C154)

2.6151

4.1999

1.2089

1

0.4265

$\mathrm{CR}=0.0151$ 


\section{Table 24(on next page)}

Local Weight of Attributes for C25 of Third Level through Fuzzy Method 


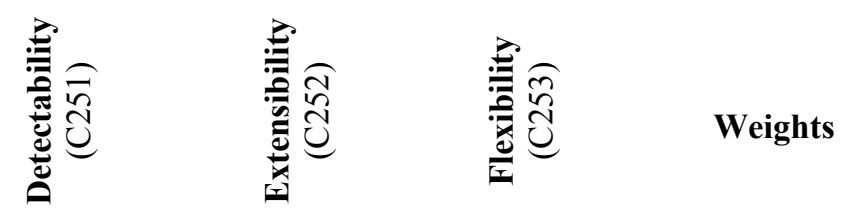

\section{Detectability}

(C251)

Extensibility

(C252)

Flexibility

(C253)

1

1.0149

0.7365

0.6147

\subsection{8}

1.6269

1

\subsection{1}

0.3873

0.2516

$$
\text { C.R. }=0.0026
$$




\section{Table 25 (on next page)}

Local Weight of Attributes for C32 of Third Level through Fuzzy Method 


\begin{tabular}{|c|c|c|c|c|c|}
\hline & 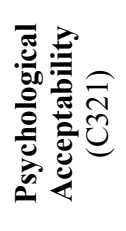 & 离产 & 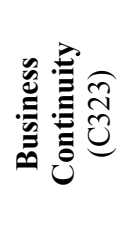 & 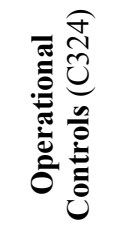 & Weights \\
\hline $\begin{array}{l}\text { Psychological } \\
\text { Acceptability } \\
\text { (C321) }\end{array}$ & 1 & 1.5973 & 1.1648 & 0.7168 & 0.2543 \\
\hline User Satisfaction (C322) & 0.6261 & 1 & 0.4561 & 0.3274 & 0.1302 \\
\hline $\begin{array}{l}\text { Business Continuity } \\
\text { (C323) }\end{array}$ & 0.8585 & & 1 & 1.0804 & 0.2829 \\
\hline $\begin{array}{l}\text { Operational Controls } \\
\text { (C324) }\end{array}$ & 1.3951 & 3.0544 & 0.9256 & 1 & 0.3326 \\
\hline & & & & & $\mathrm{CR}=0.0187$ \\
\hline
\end{tabular}

2 


\section{Table $\mathbf{2 6}$ (on next page)}

The Final Weights of Each Criterion through Hierarchy 
Table 26: The Final Weights of Each Criterion through Hierarchy

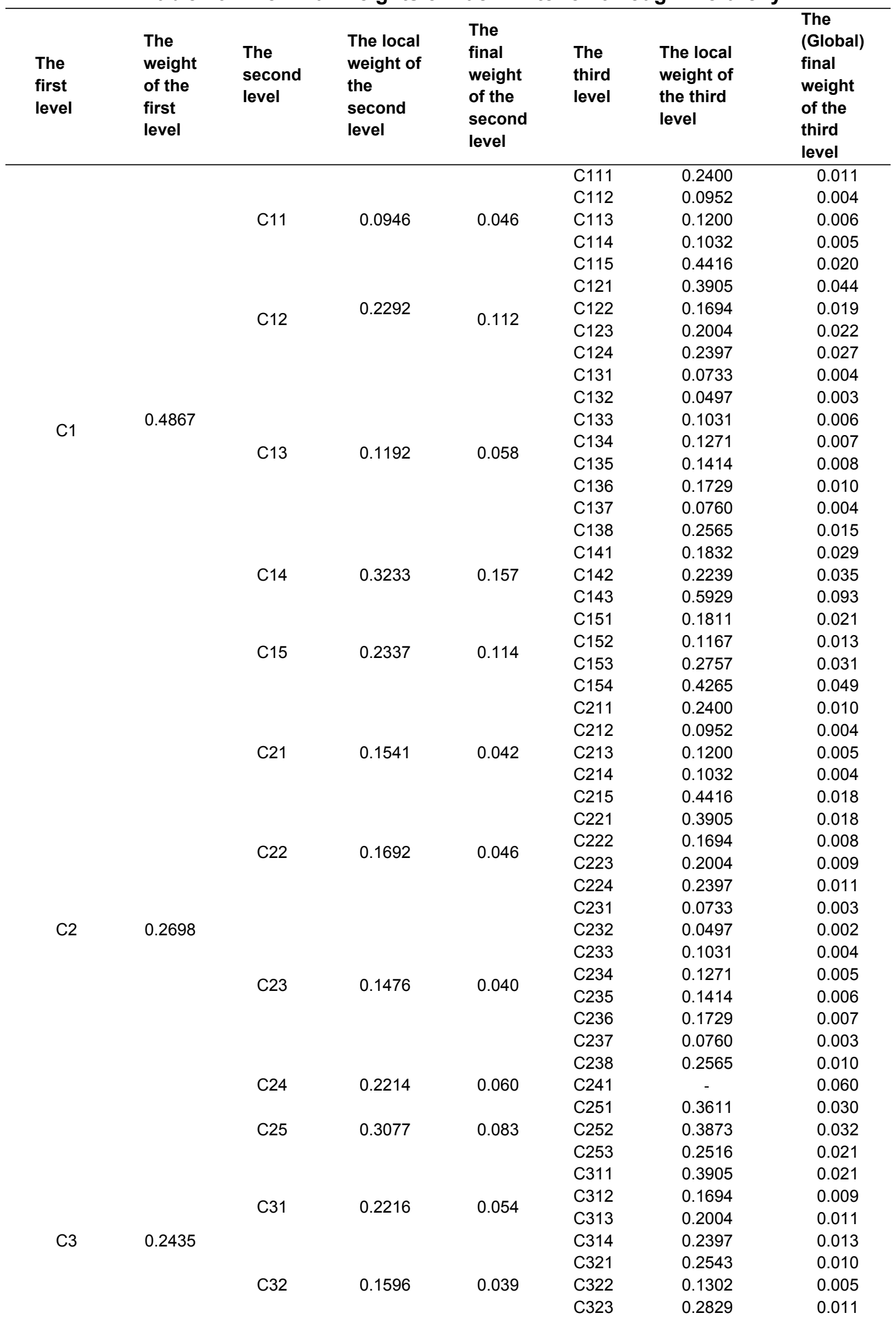




\begin{tabular}{llllll} 
& & & C324 & 0.3326 & 0.013 \\
C33 & 0.1446 & 0.035 & C331 & - & 0.035 \\
& & & C341 & 0.1832 & 0.009 \\
C34 & 0.2115 & 0.052 & C342 & 0.2239 & 0.012 \\
& & & C343 & 0.5929 & 0.031 \\
& & & C351 & 0.1811 & 0.012 \\
C35 & \multirow{2}{*}{0.2627} & 0.064 & C352 & 0.1167 & 0.007 \\
& & & C353 & 0.2757 & 0.018 \\
& & & C354 & 0.4265 & 0.027
\end{tabular}




\section{Table 27 (on next page)}

Fuzziøed Average Ratings 


\section{S. No. Characteristics of Level 1}

Old Version (Version 1)

Modified Version (Version 2)

\begin{tabular}{clcc}
\hline $\mathbf{1}$ & Dependability & $0.445,0.615$, & $0.59,0.79,0.95$ \\
$\mathbf{2}$ & Trustworthiness & 0.755 & \\
$\mathbf{3}$ & Human Trust & $0.455,0.64,0.74$ & $0.64,0.84,0.97$ \\
& & & \\
$\mathbf{S . ~ N o}$ & Characteristics of Level $\mathbf{2}$ & & \\
$\mathbf{1}$ & Reliability & $0.53,0.72,0.865$ & $0.62,0.81,0.94$ \\
$\mathbf{2}$ & Availability & $0.46,0.63,0.775$ & $0.63,0.82,0.94$ \\
$\mathbf{3}$ & Authentication & $0.38,0.55,0.71$ & $0.67,0.85,0.95$ \\
$\mathbf{4}$ & Maintainability & $0.445,0.635$, & $0.65,0.84,0.95$ \\
$\mathbf{5}$ & Confidentiality & 0.79 & $0.82,0.96$ \\
$\mathbf{6}$ & Accountability & $0.56,0.72,0.835$ & $0.51,0.70,0.86$ \\
$\mathbf{7}$ & Consumer Integrity & $0.445,0.615$, & $0.64,0.83,0.95$ \\
$\mathbf{8}$ & Survivability & 0.765 & \\
& & $0.46,0.635,0.78$ & $0.73,0.90,0.99$ \\
$\mathbf{S . ~ N o .}$ & Characteristics of Level $\mathbf{3}$ & $0.495,0.68,0.83$ & $0.69,0.87,0.98$ \\
$\mathbf{1}$ & Software Effectiveness Evaluation & & \\
$\mathbf{2}$ & User Satisfaction & $0.66,0.60,0.875$ & $0.61,0.75,0.93$ \\
$\mathbf{3}$ & Feasibility & $0.64,0.81,0.935$ & $0.52,0.64,0.84$ \\
$\mathbf{4}$ & Operational Controls & $0.49,0.57,0.835$ & $0.53,0.65,0.89$ \\
$\mathbf{5}$ & Time-efficiency & $0.75,0.67,0.985$ & $0.66,0.78,0.97$ \\
$\mathbf{6}$ & Auditability & $0.35,0.52,0.77$ & $0.69,0.85,0.99$ \\
$\mathbf{7}$ & Psychological Acceptability & $0.56,0.6,0.875$ & $0.47,0.58,0.83$ \\
$\mathbf{8}$ & Business Continuity & $0.43,0.58,0.90$ & $0.61,0.72,0.96$ \\
$\mathbf{9}$ & Accessibility & $0.42,0.57,0.905$ & $0.52,0.57,0.90$ \\
$\mathbf{1 0}$ & Extensibility & $0.49,0.61,0.795$ & $0.50,0.61,0.84$ \\
$\mathbf{1 1}$ & Flexibility & $0.44,0.60,0.89$ & $0.46,0.56,0.82$ \\
$\mathbf{1 2}$ & Detectability & $0.50,0.66,0.84$ & $0.43,0.54,0.79$ \\
$\mathbf{1 3}$ & Scalability & $0.51,0.56,0.83$ & $0.49,0.59,0.85$ \\
$\mathbf{1 4}$ & Traceability & $0.46,0.62,0.895$ & $0.51,0.66,0.85$ \\
& & $0.40,0.57,0.845$ & $0.49,0.57,0.87$
\end{tabular}




\section{Table 28 (on next page)}

Local Rating of the Attributes for Level 1, 2 and 3 through 
Table 28: Local Rating of the Attributes for Level 1, 2 and 3 through

\begin{tabular}{clcc}
\hline S. No. & Characteristics of Level 1 & $\begin{array}{c}\text { Old Version } \\
\text { (Version 1) }\end{array}$ & $\begin{array}{c}\text { Modified } \\
\text { Version } \\
\text { (Version 2) }\end{array}$ \\
\hline $\mathbf{1}$ & Dependability & 0.608 & 0.78 \\
$\mathbf{2}$ & Trustworthiness & 0.619 & 0.82 \\
$\mathbf{3}$ & Human Trust & 0.595 & 0.81
\end{tabular}

S. No. Characteristics of Level 2

$\begin{array}{llll}\mathbf{1} & \text { Reliability } & 0.709 & 0.79 \\ \mathbf{2} & \text { Availability } & 0.624 & 0.80 \\ \mathbf{3} & \text { Authentication } & 0.548 & 0.83 \\ \mathbf{4} & \text { Maintainability } & 0.626 & 0.82 \\ \mathbf{5} & \text { Confidentiality } & 0.709 & 0.69 \\ \mathbf{6} & \text { Accountability } & 0.610 & 0.81 \\ \mathbf{7} & \text { Consumer Integrity } & 0.628 & 0.88 \\ \mathbf{8} & \text { Survivability } & 0.671 & 0.85\end{array}$

\section{S. No. Characteristics of Level 3}

$\begin{array}{clll}\mathbf{1} & \text { Software Effectiveness Evaluation } & 0.626 & 0.76 \\ \mathbf{2} & \text { User Satisfaction } & 0.799 & 0.66 \\ \mathbf{3} & \text { Feasibility } & 0.616 & 0.68 \\ \mathbf{4} & \text { Operational Controls } & 0.769 & 0.79 \\ \mathbf{5} & \text { Time-efficiency } & 0.540 & 0.84 \\ \mathbf{6} & \text { Auditability } & 0.659 & 0.61 \\ \mathbf{7} & \text { Psychological Acceptability } & 0.623 & 0.75 \\ \mathbf{8} & \text { Business Continuity } & 0.616 & 0.64 \\ \mathbf{9} & \text { Accessibility } & 0.626 & 0.64 \\ \mathbf{1 0} & \text { Extensibility } & 0.633 & 0.60 \\ \mathbf{1 1} & \text { Flexibility } & 0.665 & 0.58 \\ \mathbf{1 2} & \text { Detectability } & 0.615 & 0.63 \\ \mathbf{1 3} & \text { Scalability } & 0.649 & 0.67 \\ \mathbf{1 4} & \text { Traceability } & 0.596 & 0.62\end{array}$




\section{Table 29 (on next page)}

Final Ratings of Each Attribute 
1

2
Table 29: Final Ratings of Each Attribute

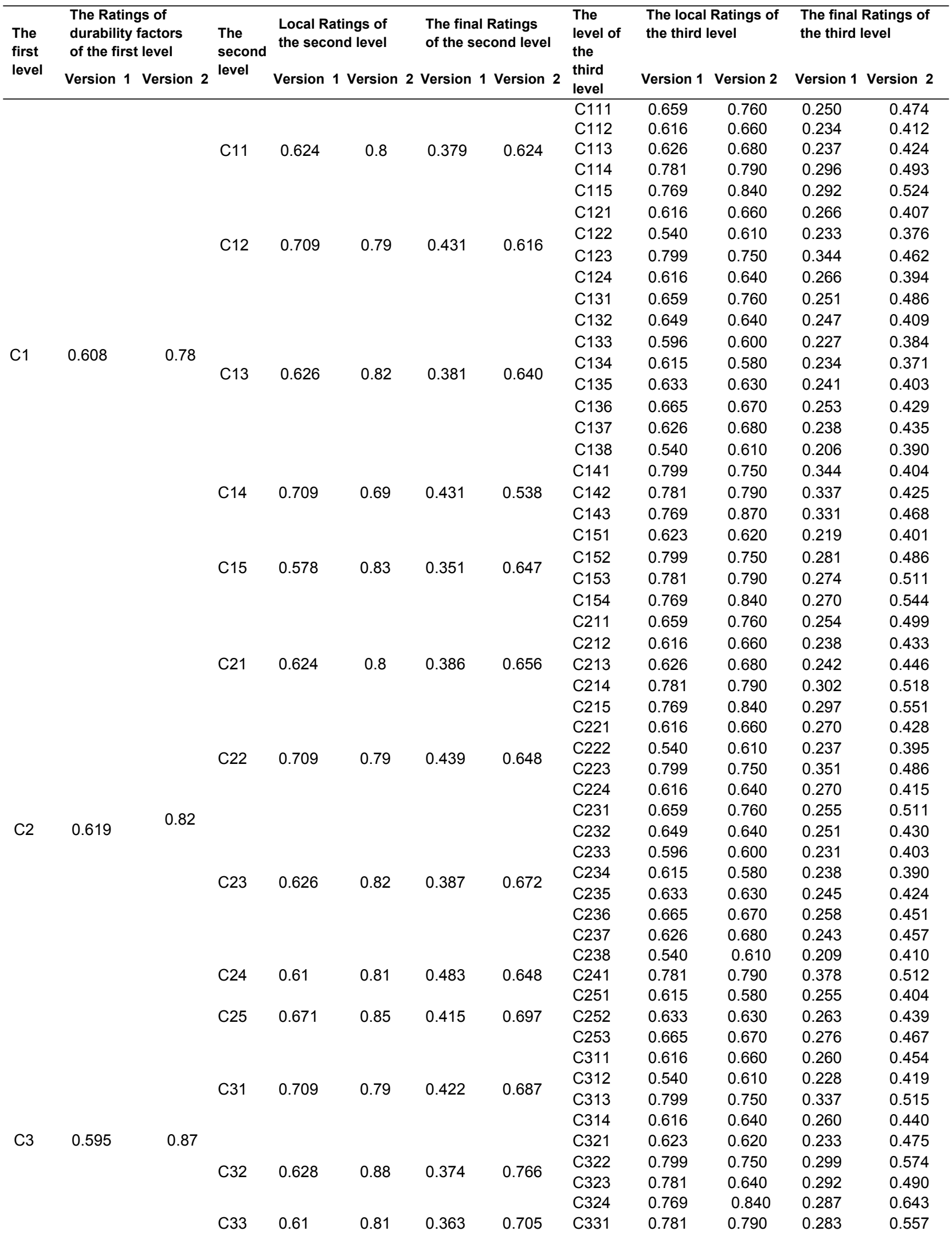




\begin{tabular}{|c|c|c|c|c|c|c|c|c|c|}
\hline & & & & & C341 & 0.799 & 0.750 & 0.337 & 0.450 \\
\hline \multirow[t]{3}{*}{ C34 } & 0.709 & 0.69 & 0.422 & 0.600 & C342 & 0.781 & 0.790 & 0.329 & 0.474 \\
\hline & & & & & C343 & 0.769 & 0.840 & 0.324 & 0.504 \\
\hline & & & & & C351 & 0.623 & 0.620 & 0.203 & 0.448 \\
\hline \multirow{3}{*}{ C35 } & 0510 & ?० & & ת7 0 & C352 & 0.799 & 0.750 & 0.261 & 0.542 \\
\hline & 0.548 & 0.83 & 0.326 & 0.122 & C353 & 0.781 & 0.790 & 0.255 & 0.570 \\
\hline & & & & & C354 & 0.769 & 0.840 & 0.251 & 0.607 \\
\hline
\end{tabular}

3

4 


\section{Table $\mathbf{3 0}$ (on next page)}

Overall Security Durability 


\begin{tabular}{lcc}
\hline & Version 1 & Version 2 \\
\hline Security Durability & 0.2852 & 0.4700
\end{tabular}

2

3 


\section{Table 31(on next page)}

Security Durability Impact at Level 1 
Table 31: Security Durability Impact at Level 1

\begin{tabular}{clcc}
\hline & \multicolumn{4}{c}{ The contribution of Security Durability at Level 1 } \\
\hline S. No. & Characteristics of Level 1 & Version 1 & Version 2 \\
$\mathbf{1}$ & Dependability & 0.1391 & 0.2187 \\
$\mathbf{2}$ & Trustworthiness & 0.0782 & 0.1246 \\
$\mathbf{3}$ & Human Trust & 0.0679 & 0.1267
\end{tabular}

2 


\section{Table 32 (on next page)}

Security Durability Impact at Level 2 
1

Table 32: Security Durability Impact at Level 2

The Contribution of Security Durability at Level 2

\begin{tabular}{rlrr}
\hline S. & Characteristics of Level $\mathbf{2}$ & Version $\mathbf{1}$ & Version $\mathbf{2}$ \\
No. & & 0.0584 & 0.0903 \\
$\mathbf{1}$ & Reliability & 0.0237 & 0.0433 \\
$\mathbf{2}$ & Availability & 0.0456 & 0.0931 \\
$\mathbf{3}$ & Authentication & 0.0227 & 0.0403 \\
$\mathbf{4}$ & Maintainability & 0.0696 & 0.0955 \\
$\mathbf{5}$ & Confidentiality & 0.0326 & 0.0502 \\
$\mathbf{6}$ & Accountability & 0.0108 & 0.0214 \\
$\mathbf{7}$ & Consumer Integrity & 0.0219 & 0.0360 \\
$\mathbf{8}$ & Survivability & &
\end{tabular}

2 


\section{Table 33 (on next page)}

Security Durability Impact at Level 3 
1

Table 33: Security Durability Impact at Level 3

The Contribution of Security Durability at Level 3

\begin{tabular}{llll}
\hline S. Nc & Characteristics of Level 3 & Version $\mathbf{1}$ & Version $\mathbf{2}$ \\
$\mathbf{1}$ & Software Effectiveness & 0.0641 & 0.1014 \\
$\mathbf{2}$ & Evaluation & 0.0344 & 0.0490 \\
$\mathbf{3}$ & User Satisfaction & 0.0239 & 0.0385 \\
$\mathbf{4}$ & Opeasibility & 0.0758 & 0.1310 \\
$\mathbf{5}$ & Time-efficiency & 0.0136 & 0.0240 \\
$\mathbf{6}$ & Auditability & 0.0071 & 0.0137 \\
$\mathbf{7}$ & Psychological Acceptability & 0.0094 & 0.0185 \\
$\mathbf{8}$ & Business Continuity & 0.0167 & 0.0263 \\
$\mathbf{9}$ & Accessibility & 0.0043 & 0.0079 \\
$\mathbf{1 0}$ & Extensibility & 0.0118 & 0.0198 \\
$\mathbf{1 1}$ & Flexibility & 0.0101 & 0.0173 \\
$\mathbf{1 2}$ & Detectability & 0.0105 & 0.0167 \\
$\mathbf{1 3}$ & Scalability & 0.0012 & 0.0021 \\
$\mathbf{1 4}$ & Traceability & 0.0023 & 0.0039
\end{tabular}




\section{Table 34(on next page)}

Sensitivity Analysis Due to $\square$ and $\square$ Values 
3

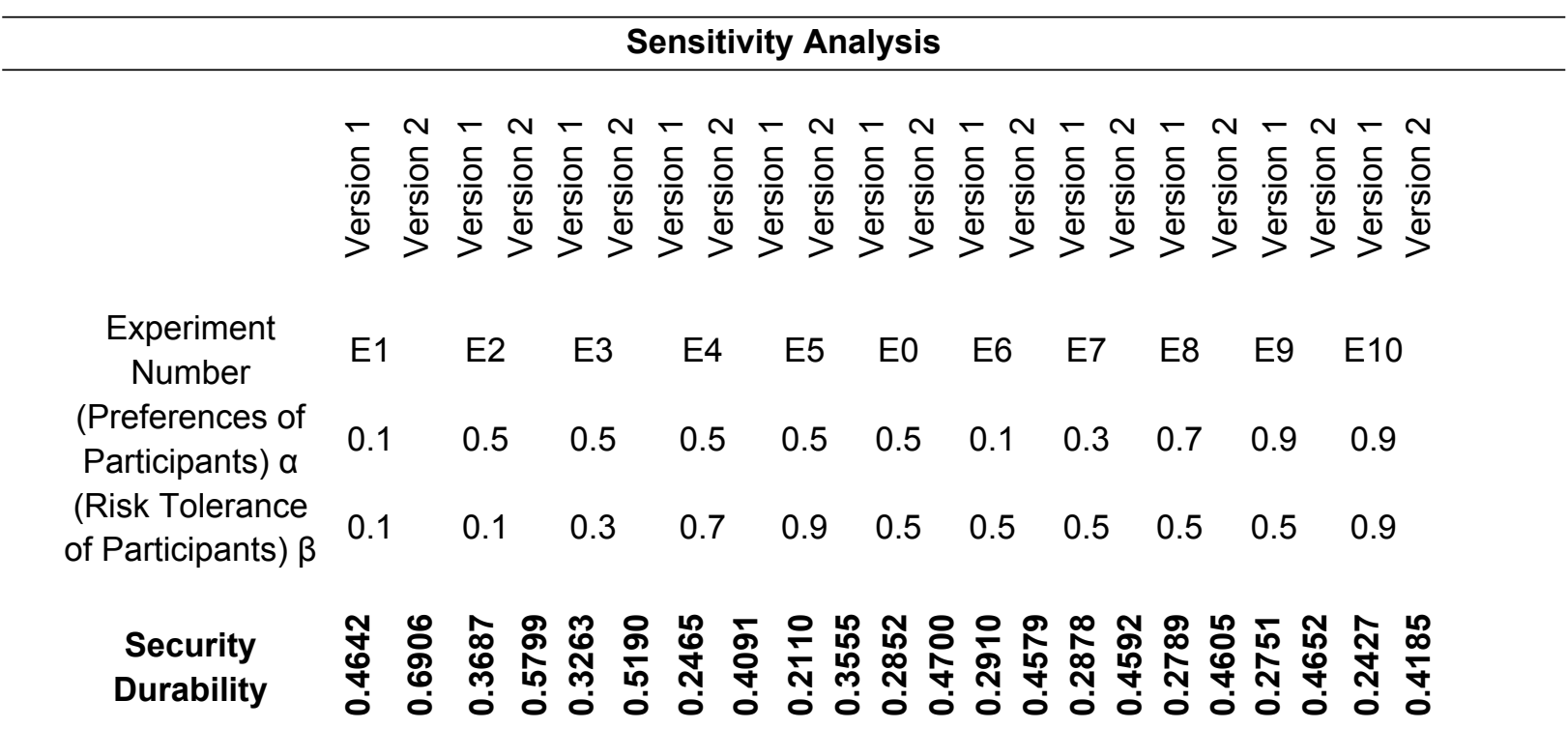

\section{4}

5 